\title{
Artemisinins in Combating Viral Infections Like SARS-CoV-2, Inflammation and Cancers and Options to Meet Increased Global Demand
}

\author{
Karim Farmanpour-Kalalagh ${ }^{1}$, Arman Beyraghdar Kashkooli ${ }^{*}$, Alireza Babaei ${ }^{1}$, \\ Ali Rezaei ${ }^{1}$ and Alexander R. van der Krol ${ }^{2}$
}

${ }^{1}$ Department of Horticultural Science, Faculty of Agriculture, Tarbiat Modares University, Tehran, Iran, ${ }^{2}$ Laboratory of Plant Physiology, Wageningen University and Research, Wageningen, Netherlands

\section{OPEN ACCESS}

Edited by:

Linda Avesani,

University of Verona, Italy

Reviewed by:

Juan Moisés De La Serna, Universidad Internacional De La Rioja,

Spain

Stefano Negri,

University of Verona, Italy

*Correspondence: Arman Beyraghdar Kashkooli a.beyraghdar@modares.ac.ir

Specialty section:

This article was submitted to

Plant Biotechnology,

a section of the journal

Frontiers in Plant Science

Received: 20 September 2021

Accepted: 03 January 2022

Published: 07 February 2022

Citation:

Farmanpour-Kalalagh $\mathrm{K}$

Beyraghdar Kashkooli A, Babaei A, Rezaei A and van der Krol AR (2022)

Artemisinins in Combating Viral Infections Like SARS-CoV-2,

Inflammation and Cancers

and Options to Meet Increased Global Demand. Front. Plant Sci. 13:780257.

doi: 10.3389/fp/s.2022.780257
Artemisinin is a natural bioactive sesquiterpene lactone containing an unusual endoperoxide 1, 2, 4-trioxane ring. It is derived from the herbal medicinal plant Artemisia annua and is best known for its use in treatment of malaria. However, recent studies also indicate the potential for artemisinin and related compounds, commonly referred to as artemisinins, in combating viral infections, inflammation and certain cancers. Moreover, the different potential modes of action of artemisinins make these compounds also potentially relevant to the challenges the world faces in the COVID-19 pandemic. Initial studies indicate positive effects of artemisinin or Artemisia spp. extracts to combat SARS-CoV-2 infection or COVID-19 related symptoms and WHO-supervised clinical studies on the potential of artemisinins to combat COVID-19 are now in progress. However, implementing multiple potential new uses of artemisinins will require effective solutions to boost production, either by enhancing synthesis in $A$. annua itself or through biotechnological engineering in alternative biosynthesis platforms. Because of this renewed interest in artemisinin and its derivatives, here we review its modes of action, its potential application in different diseases including COVID-19, its biosynthesis and future options to boost production.

Keywords: Artemisia annua, artemisinin, CoVID-19, malaria, SARS-CoV-2, sesquiterpene lactone

\section{INTRODUCTION}

Artemisinin is an oxygenated sesquiterpene lactone, mostly produced in glandular trichomes (GTs) of the medicinal plant Artemisia annua L. (Tang et al., 2014; Wang et al., 2016; Beyraghdar Kashkooli et al., 2018, 2019). Artemisinin and related compounds derived from the biosynthetic pathway (Figure 1) have been shown to be effective against malaria caused by the Plasmodium spp. parasite (Klayman, 1985; Tu, 2011). The action of artemisinin is not only on the Plasmodium itself, but also because of its effect on human physiology. It is the effects of artemisinin on human physiology that relate to its potential uses in other diseases as well. Below the mode of action of artemisinin and related compounds in Plasmodium and humans are discussed, exemplified by its potential use in the fight against COVID-19. 


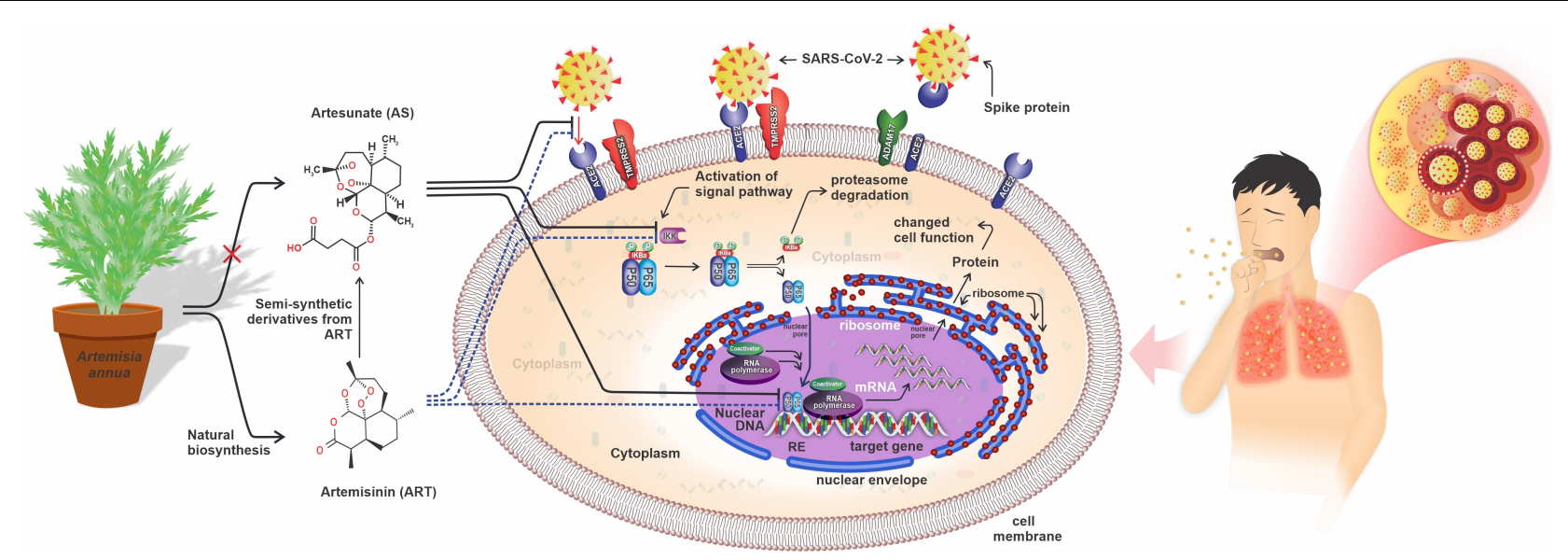

GRAPHICAL ABSTRACT | Three anti-SARS-CoV-2 potentials of artemisinin and artesunate. Artemisinin (ART) and artesunate (AS) may (1) block interaction of viral spike protein with the human ACE2 receptors, preventing viral endocytosis and activation of the NF-kB signaling pathway, (2) ART and AS may block activation of NF-кB signaling pathway by IKK, or (3) may interfere directly with p50/p65 transcriptional activity in human cells.

Because of the alternative uses of artemisinin, including the fight against COVID-19, the renewed demand for this compound cannot be met by current production capacity. Therefore, also current production capacity problems and potential solutions are briefly discussed.

\section{ARTEMISININ: MODES OF ACTION IN THE MALARIA Plasmodium PARASITIC CELLS}

Artemisinin contains an endoperoxide bridge that is important for anti-malarial activity. In general, several mechanisms of actions have been proposed to explain the bioactivity of artemisinin against Plasmodium spp. (O'Neill et al., 2010). The first proposed action is the interference with Plasmodium mitochondrial and plasma functions (Antoine et al., 2014). Studies have shown that artemisinin/artemisinin semi-synthetic derivatives (totally known as endoperoxides) induce Plasmodium mitochondrial and plasma membrane depolarization (Wang J. et al., 2010; Antoine et al., 2014). These membrane depolarizations are strongly associated with Reactive Oxygen Species (ROS) that are generated by iron bioactivation of the endoperoxides of artemisinin (Antoine et al., 2014; Wang J. et al., 2015; Tilley et al., 2016). An additional mode of action of artemisinin against the onset of malaria is based on the cleavage of the endoperoxide in the artemisinin molecule, resulting in artemisinin free radicals, which act as alkylation agent for susceptible molecules and proteins in the parasitic cell. For instance, the alkylation of Plasmodium falciparum TCTP, ATP6 (a Ca ${ }^{2+}$ transporter) (Shandilya et al., 2013) and PI3K (Mbengue et al., 2015) may interfere with the biological function of these proteins in the infection process. In infected red blood cells, the malaria parasite degrades hemoglobin (as a source of amino acids), resulting in large amounts of free heme molecules. These are potentially toxic to the malaria parasite but are detoxified by the parasite via conversion of heme to hemozoin. The alkylation of heme by activated artemisinin could inhibit this detoxification reaction to hemozoin. In a more general sense, the alkylation of parasitic proteins may also interfere with their correct folding, which in turn may be linked to decreased parasite development. Indeed, treatment with artemisinin results in an upregulation of the Unfolded Protein Response (UPR) (Mok et al., 2015). In addition to artemisinin, dihydroartemisinin attacks parasites by using a two-pronged process, creating protein damage, and endangering parasite proteasome function. The consequent gradual accumulation of proteasome substrates (i.e., polyubiquitinated and unfolded/damaged proteins) results in the endoplasmic reticulum stress and dihydroartemisinin-mediated death of the parasite. Tests with other specific inhibitors of the proteasome create a similar increase of polyubiquitinated proteins, also causing parasite death (Bridgford et al., 2018) (Figure 2).

\section{ARTEMISININS: POTENTIAL MODES OF ACTION IN HUMAN INFLAMMATION RESPONSES}

Besides its role in combating malaria, artemisinin has also been investigated for its potential effect on immune responses under physiological and pathological conditions (Efferth et al., 2002; Aldieri et al., 2003; Xu et al., 2007; Gu et al., 2012; Lai et al., 2015; Yu et al., 2016; Nunes et al., 2017). Many bacteria and viruses, including the SARS-CoV-2, activate the NF- $\mathrm{B}$ (Nuclear Factor kappa B) signaling pathway in human cells. $\mathrm{NF}-\kappa \mathrm{B}$ is a transcription factor that regulates multiple aspects of innate and adaptive immune functions and has a central role in inflammatory responses. For instance, NF-кB induces the expression of pro-inflammatory genes like those encoding cytokines and chemokines. NF- $\kappa \mathrm{B}$ is a heterodimeric protein complex consisting of $\mathrm{p} 50 / \mathrm{p} 65$ which is retained in the cytosol 


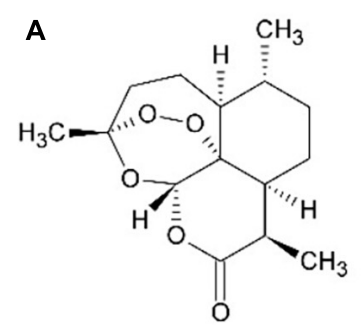

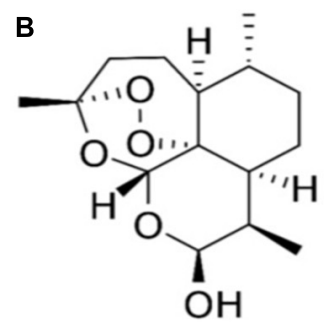

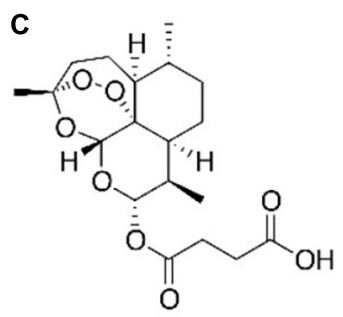

FIGURE 1 | Chemical structure of artemisinin and related compounds: artemisinin (A), dihydroartemisinin, another biosynthetic pathway product and also known as dihydroqinghaosu, or artenimol (B) and artesunate, which is a semi-synthetic chemical derivative of artemisinin biosynthetic pathway product (C).

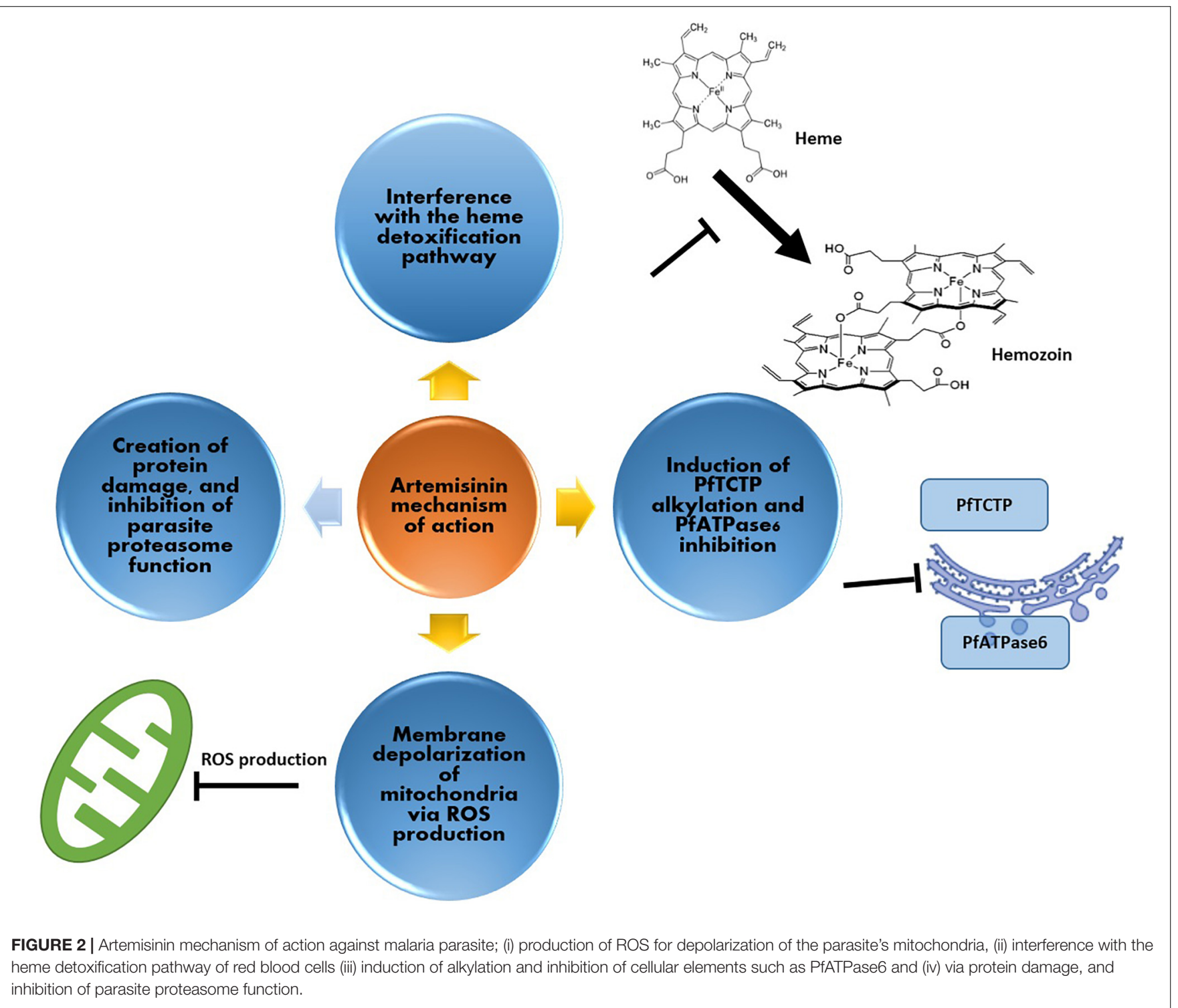

by interaction with IкB $\alpha$ (Verma et al., 1995). Activation of NF$\kappa \mathrm{B}$ signaling activates the IкB kinase activity which results in the release of $\mathrm{p} 50 / \mathrm{p} 65$ from IкB $\alpha$ and subsequent movement of p50/p65 to the nucleus where it leads to the expression of specific genes and the production of pro-inflammatory chemokines and cytokines like Interleukin 6 (IL-6) (Verma et al., 1995; Pahl, 1999; Xiong et al., 2010; Liu et al., 2017; Figure 2). IL-6, is a pleiotropic cytokine that is produced in response to infection, tissue-damaging, cellular immune response, and hematopoiesis to contribute and help the host's defense system 
(Tanaka et al., 2014; Velazquez-Salinas et al., 2019). Normally, the production of IL- 6 is strictly regulated at transcriptional and post-transcriptional levels. However, certain diseases, like in COVID-19, may cause misregulation of the NF- $\kappa$ B signaling, causing overproduction of IL- 6 and other cytokines in a cytokine release syndrome (CRS) (Tanaka et al., 2014; Conti and Younes, 2020; Krishna et al., 2021). Indeed, the dynamic change of IL-6 level can be used as a potential biomarker for a severe case of COVID-19 (Liu et al., 2020; Ulhaq and Soraya, 2020; Zhu et al., 2020). In addition to IL-6, also other factors including interferon $\gamma$, tumor necrosis factor (TNF), and Interleukin 1 (IL-1), etc., are over-produced during CRS and contribute to pathophysiological processes and multi-organ dysfunction (MOD) (Krishna et al., 2021). The cytokine storm (CS) during CRS may be brought under control by artemisinin or artesunate treatment as these block NF- $\mathrm{B}$ signaling by inhibiting IKK activity (Efferth et al., 2002; Aldieri et al., 2003; Xu et al., 2007; Gu et al., 2012; Lai et al., 2015; Nunes et al., 2017; Efferth and Oesch, 2021). The activation of NF- $\kappa \mathrm{B}$ signaling results in the downstream activation of the p50/p65 transcription factors, and artemisinin and artesunate may also act as an inhibitor in the NF- $\mathrm{B}$ signaling pathway by blocking the function of p50/p65 in transcriptional activation of target genes like IL-6.

\section{ARTEMISININS: POTENTIAL MODES OF ACTION IN FIGHTING HUMAN CANCERS}

Artemisinins have been used to combat many different types of cancers and different modes of action have been described (Table 1). One of the most important mechanisms is preventing the activation of NF- $\kappa \mathrm{B}$ signaling pathway involved in tumor induction, initiation, and progression of many cancerous cell lines. It is noteworthy that artemisinin may affect NF- $\kappa B$ signaling at different levels: it inhibits initiation of nuclear signaling by preventing interaction of p65 and p50 to cytosolic IKK, but in the nucleus it also inhibits interaction of p50 and p65 with target promoters (Tran et al., 2014) (see GRAPHICAL ABSTRACT). Also, Helicobacter pylori-induced gastric oncogenesis is inhibited by artemisinins through blocking $\mathrm{NF}-\kappa \mathrm{B}$ signaling. Remarkably in gastric cancer, artemisinins reverse the $I \kappa \mathrm{B} \alpha$ level, prevent NF- $\kappa \mathrm{B}$ pathway in a dosedependent manner, and decrease the generation of downstream inflammatory factors such as TNF- $\alpha$ (tumor necrosis factor$\alpha$ ) and IL-8 (interleukin-8) (Su et al., 2019). The artemisinin related compound dihydroartemisinin induces autophagy via suppressing NF- $\kappa \mathrm{B}$ pathway in myeloma, colorectal, and cervical cancer cell lines ( $\mathrm{Hu}$ et al., 2014), while the anti-invasive activity of dihydroartemisinin may occur through preventing of $\mathrm{PKCa} / \mathrm{Raf} / \mathrm{ERK}$ and JNK phosphorylation and decreasing NF- $\kappa B$ (Hwang et al., 2010). Indeed, increasing $\operatorname{IkB} \alpha$ protein and blocking p65 subunit in NF- $\mathrm{B}$ pathway is boosted by dihydroartemisinin (Dong et al., 2014).

Artesunate attenuates the growth of cancer cells and thus the development of the tumor by targeting NF- $\mathrm{B}$ pathway (Table 1). In prostate cancer cells, resistance to androgen receptor antagonists is reduced by using artesunate.
Mechanistically, the combination of artesunate and bicalutamide prevents NF- $\kappa \mathrm{B}$ pathway by ubiquitin-mediated proteasomal deterioration (Nunes et al., 2017). In attempts to treat cervical cancer, the evidence demonstrated that artesunate successfully increases tumor necrosis factor-related apoptosisinducing ligand (TRAIL)-mediated cytotoxicity via pro-survival proteins including $\mathrm{X}$-linked inhibitor of apoptosis protein (XIAP), survivin, and B-cell lymphoma-extra-large (Bcl-xL), and reduces the number of survival proteins in HeLa cells. The downregulation of mentioned proteins can be regulated by repressing activation of serine/threonine-protein kinase and NF- $\kappa \mathrm{B}$ signaling. Artesunate further prevents TRAIL-influenced transcriptional activity of NF- $\kappa \mathrm{B}$ (Thanaketpaisarn et al., 2011).

\section{ARTEMISININS: POTENTIALS IN COMBATING COVID-19 AND OTHER HUMAN VIRAL INFECTIONS}

\section{Physiological Effects of Artemisinins or Artemisia spp. Plant Extracts}

Currently, we are facing the serious challenge of the COVID-19 pandemic, which has disrupted global health and the economy. COVID-19 is a virus-related disease similar to Severe Acute Respiratory Syndrome CoronaVirus (SARS-CoV) (Lu et al., 2020) and is caused by the SARS-CoV-2 (Lai et al., 2020; Singhal, 2020). Unlike with SARS-CoV, patients infected with SARS-CoV-2 initially have mild symptoms and continue their daily activities, but in the meantime are infectious to others (Heymann and Shindo, 2020; Zheng et al., 2020). In some patients, disease symptoms may suddenly increase dramatically due to the development of a CS entitled CRS with hallmarks in the body of inflammation and immunosuppression (Mehta et al., 2020). CRS in COVID-19 patients may result in respiratory failures that create Acute Respiratory Distress Syndrome (ARDS) and MOD (Krishna et al., 2021). While worldwide efforts are aimed at vaccines that may prevent infection by COVID-19, additional medicines that can alleviate the severe symptoms of COVID-19 are still a high priority, also because new viral variants may escape vaccine recognition.

Previously, in vitro studies have indicated that the alkylating activity of activated artemisinin (as discussed above in the context of malaria) or the specific structure of artemisinin may have potential in preventing infections by members of the Herpesviridae family (e.g., herpes simplex virus type 1, EpsteinBarr virus, human cytomegalovirus), hepatitis B virus, hepatitis $\mathrm{C}$ virus, and bovine viral diarrhea virus (Efferth et al., 2008; Efferth, 2018). Artemisinin also has received renewed attention to fight emerging new viruses for which no effective antiviral drugs are available (e.g., HIV, dengue virus, chikungunya virus, Ebola virus), against viral strains that have developed drug resistance (e.g., human cytomegalovirus) and most recently against Coronavirus (D'alessandro et al., 2020). To combat infection by COVID19, extracts from different medicinal plants (including from Artemisia spp.) have been tested against COVID-19 (Bahrami et al., 2020; Bailly and Vergoten, 2020; Huang et al., 2020; 
TABLE 1 | Artemisinins effects/mechanisms of action in combating various cancers.

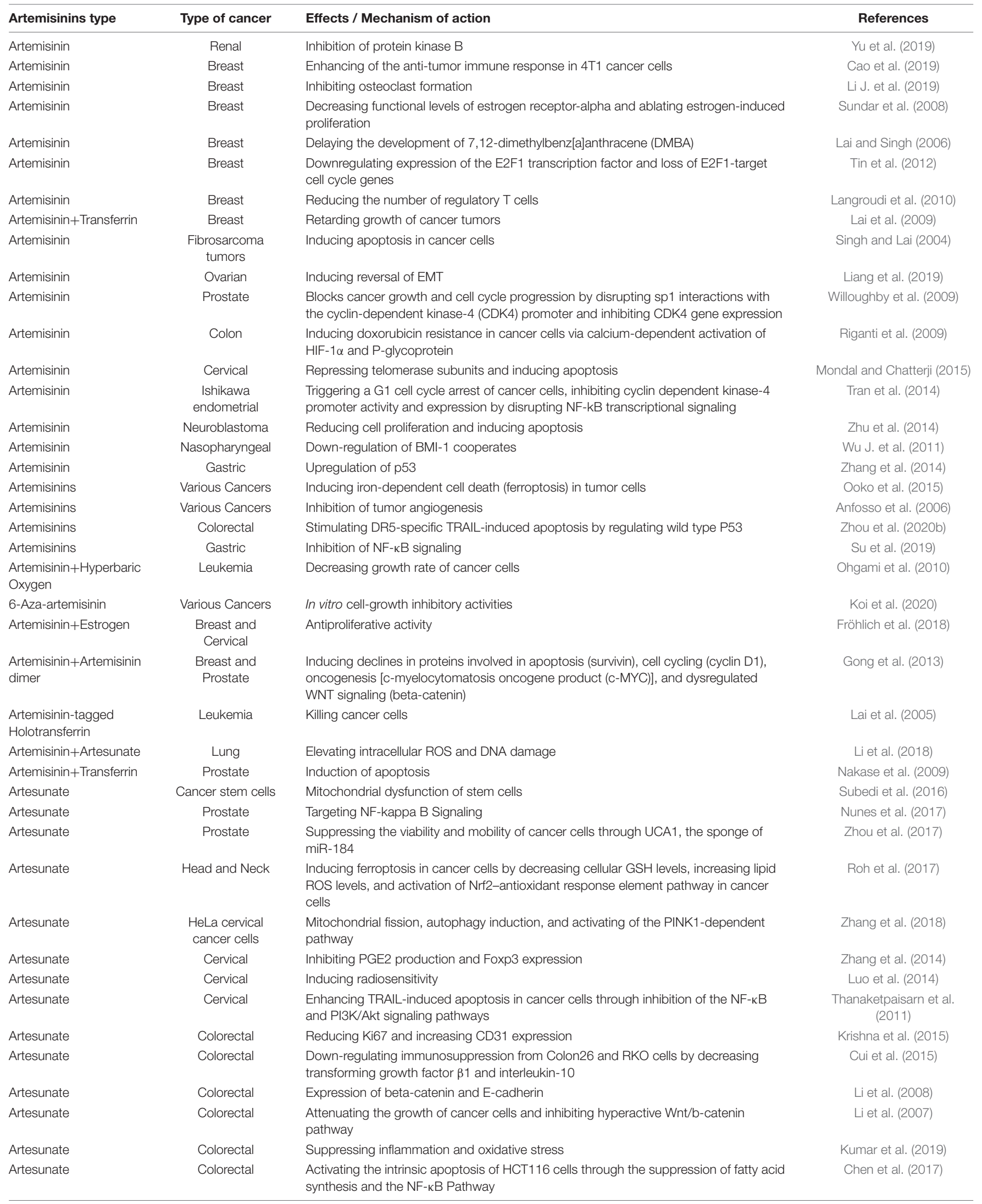


TABLE 1 | (Continued)

\begin{tabular}{|c|c|c|c|}
\hline Artemisinins type & Type of cancer & Effects / Mechanism of action & References \\
\hline Artesunate & Colorectal & $\begin{array}{l}\text { Down-regulating of } \beta \text {-catenin, suppressing of angiogenesis, cellular proliferating and } \\
\text { inducing of apoptosis }\end{array}$ & Verma et al. (2017) \\
\hline Artesunate & Bladder & $\begin{array}{l}\text { Inducing autophagy dependent apoptosis through upregulating ROS and activating } \\
\text { AMPK-mTOR-ULK1 axis }\end{array}$ & (Zhou et al., 2020a) \\
\hline Artesunate & Leukemia & $\begin{array}{l}\text { Inhibiting angiogenesis and down-regulating vascular endothelial growth factor } \\
\text { expression }\end{array}$ & Zhou et al. (2007) \\
\hline Artesunate & $\begin{array}{l}\text { T-cell leukemia/ } \\
\text { lymphoma }\end{array}$ & Increasing of intracellular ROS and activation of the DNA damage marker $\gamma-\mathrm{H} 2 \mathrm{AX}$ & Ishikawa et al. (2020) \\
\hline Artesunate & Skin & $\begin{array}{l}\text { Induction of G0/G1 cell cycle arrest and iron-mediated } \\
\text { mitochondrial apoptosis }\end{array}$ & Jiang et al. (2012) \\
\hline Artesunate & Liver & Inducing G0/G1 cell cycle arrest and apoptosis via increasing intracellular ROS & Yin et al. (2020) \\
\hline Artesunate & Liver & $\begin{array}{l}\text { Mitigating proliferation of tumor cells by alkylating heme-harboring nitric oxide } \\
\text { synthase }\end{array}$ & Zeng and Zhang (2011) \\
\hline Artesunate & Laryngeal & Reducing of tumor proliferation & Singh and Verma (2002) \\
\hline Artesunate & Ovarian & $\begin{array}{l}\text { Promoting Th1 differentiation from CD4+ T cells to enhance cell apoptosis via } \\
\text { miR-142 }\end{array}$ & Chen et al. (2019) \\
\hline Artesunate & Ovarian & sensitizing cancer cells to cisplatin by downregulating RAD51 & Wang B. et al. (2015) \\
\hline Artesunate & Ovarian & Inhibiting cancer cell growth and proliferation & Greenshields et al. (2017) \\
\hline Artesunate & Ovarian & Reducing cell viability & McDowell et al. (2021) \\
\hline Artesunate & Glioblastoma & $\begin{array}{l}\text { Inducing oxidative DNA damage, sustaining DNA double-strand breaks, and the } \\
\text { ATM/ATR damage response }\end{array}$ & Berdelle et al. (2011) \\
\hline Artesunate & Rhabdomyosarcoma & Inducing ROS and p38 MAPK-mediated apoptosis and counteracting tumor growth & Beccafico et al. (2015) \\
\hline Artesunate & Merkel cell carcinoma & $\begin{array}{l}\text { Affecting T antigen expression and repressing growth and survival of MCPyV-positive } \\
\text { cancer cells }\end{array}$ & Sarma et al. (2020) \\
\hline Artesunate & Breast & Inhibition of the growth of MCF-7 tumor cell & Dong and Wang (2014) \\
\hline Artesunate & Breast & Inducing apoptosis pathway by loading into lipid carriers & Tran et al. (2016) \\
\hline Artesunate & Breast & Induction of apoptosis & Jamalzadeh et al. (2017) \\
\hline Artesunate & Breast & Enhancing the efficacy of 5-ALA-based SDT & Osaki et al. (2017) \\
\hline Artesunate & Breast & $\begin{array}{l}\text { Activating mitochondrial apoptosis in cancer cells via iron-catalyzed lysosomal ROS } \\
\text { production }\end{array}$ & $\begin{array}{l}\text { Hamacher-Brady et al. } \\
\qquad(2011)\end{array}$ \\
\hline Artesunate & Breast & $\begin{array}{l}\text { Inducing G2/M cell cycle arrest through autophagy } \\
\text { induction }\end{array}$ & Chen et al. (2014) \\
\hline Artesunate & Breast & $\begin{array}{l}\text { Down-regulating the expression of } \mathrm{Bcl}-2 \text { and HSP70, Enhancing the expression of } \\
\text { cleaved caspase- } 9 \text { in MCF-7 and } 4 \mathrm{~T} 1 \text { cells }\end{array}$ & Pirali et al. (2020) \\
\hline Artesunate & Breast & Promoting G2/M cell cycle arrest in MCF7 cancer cells through ATM activation & Wen et al. (2018) \\
\hline Artesunate & Endometrial & $\begin{array}{l}\text { Suppressing the proliferation and development of estrogen receptor- } \alpha \text {-positive in } \\
\text { HAND2-dependent pathway }\end{array}$ & Yin et al. (2021) \\
\hline Artesunate & Lung & $\begin{array}{l}\text { Inhibiting invasion and in vivo metastasis in cancer cells by targeting essential } \\
\text { extracellular proteases }\end{array}$ & Rasheed et al. (2010) \\
\hline Artesunate & Lung & Expression of EGFR and ABCG2 & Ma et al. (2011) \\
\hline Artesunate & Bladder & Inducing apoptosis of cancer cells by miR-16 regulation of COX-2 expression & Zuo et al. (2014) \\
\hline Artesunate & Bladder & $\begin{array}{l}\text { Impairing growth in cisplatin-resistant cancer cells by cell cycle arrest, apoptosis and } \\
\text { autophagy induction }\end{array}$ & Zhao et al. (2020) \\
\hline Artesunate & Colon & Enhancing ablation effect on xenograft cancer cells & Hao et al. (2020) \\
\hline Artesunate & Colon & Inducing apoptosis and autophagy & Jiang et al. (2018) \\
\hline Artesunate & $\begin{array}{c}\text { Nitrosodiethylamine } \\
\text { mediated } \\
\text { experimental } \\
\text { hepatocellular model }\end{array}$ & Suppression of IL-6-JAK-STAT signaling & Ilamathi et al. (2016) \\
\hline Artesunate & HeLa and HepG2 cells & $\begin{array}{l}\text { Inducing cell death in cancer cells via enhancing lysosomal function and lysosomal } \\
\text { degradation of ferritin }\end{array}$ & Yang et al. (2014) \\
\hline Artesunate & Non-small-cell lung & $\begin{array}{l}\text { Inhibiting epithelial-mesenchymal transition in cancer cells by down-regulating the } \\
\text { expression of BTBD7 }\end{array}$ & Wang et al. (2020) \\
\hline Artesunate & Non-small cell lung & $\begin{array}{l}\text { Enhancing radiosensitivity cancer cells via increasing NO production to induce cell } \\
\text { cycle arrest at G2/M phase }\end{array}$ & Zhao et al. (2011) \\
\hline Artesunate & Pancreatic & Inducing AsPC-1 and PaTU8988 cell death & Wang K. et al. (2019) \\
\hline Artesunate & Pancreatic & Activating of ferroptosis & Eling et al. (2015) \\
\hline Artesunate & Gastric & & Wang et al. (2017) \\
\hline Artesunate & Gastric & Inhibiting the growth of cancer cells through the mechanism of promoting oncosis & Zhou et al. (2013) \\
\hline Artesunate & Gastric & Inhibiting cancer cell growth and inducing apoptosis by down-regulating COX-2 & Zhang et al. (2015) \\
\hline Artesunate & B-cell lymphoma & Suppressing cancer cell growth and metabolism & Våtsveen et al. (2018) \\
\hline
\end{tabular}


TABLE 1 | (Continued)

\begin{tabular}{|c|c|c|c|}
\hline Artemisinins type & Type of cancer & Effects / Mechanism of action & References \\
\hline Artesunate & Bone metastasis & $\begin{array}{l}\text { Suppressing RANKL-induced osteoclastogenesis through inhibition of } \\
\text { PLC } \gamma 1-\mathrm{Ca}^{2+} \text { - NFATc1 signaling pathway and preventing ovariectomy-induced } \\
\text { bone loss }\end{array}$ & Zeng et al. (2017) \\
\hline Artesunate & Esophageal & Cell apoptosis and suppressing the proliferation & Shi et al. (2015) \\
\hline Artesunate & Esophageal & Enhancing radiosensitivity of cancer cells by inhibiting the repair of DNA damage & Fei et al. (2018) \\
\hline Artesunate & Dermal fibroblasts & $\begin{array}{l}\text { Inhibiting myofibroblast formation via induction of apoptosis and antagonism of } \\
\text { pro-fibrotic gene expression }\end{array}$ & Larson et al. (2019) \\
\hline $\begin{array}{l}\text { Artesunate+Histone } \\
\text { Deacetylase Inhibitors }\end{array}$ & $\begin{array}{l}\text { Hepatocellular, } \\
\text { Colorectal, Lung, } \\
\text { and Pancreatic }\end{array}$ & Elevating heme synthesis via synergistic upregulation of ALAS1 expression & Chen et al. (2019) \\
\hline Artesunate+Ferrous iron & $\begin{array}{l}\text { Leukemia and } \\
\text { Astrocytoma }\end{array}$ & Induction of apoptosis & Efferth et al. (2004) \\
\hline Artesunate+Sorafenib & Liver & Inhibiting cancer cell growth and apoptosis induction & Li H. et al. (2019) \\
\hline Artesunate+Cisplatin & Lung & Inhibiting MAPK pathway & Li W. et al. (2021) \\
\hline $\begin{array}{l}\text { Artesunate and } \\
\text { Dihydroartemisinin }\end{array}$ & Neuroblastoma & Inducing apoptosis and ROS in cancer cells & Michaelis et al. (2010) \\
\hline Artesunate+Connexin-43 & Renal and Breast & DNA damage and enhancing the bystander apoptosis of the neighboring cells & Raza et al. (2017) \\
\hline Artesunate+Allicin & Osteosarcoma & Inhibiting cell proliferation and apoptosis & Jiang et al. (2013) \\
\hline $\begin{array}{l}\text { Artesunate and } \\
\text { Dihydroartemisinin }\end{array}$ & Epithelial ovarian & $\begin{array}{l}\text { Inhibiting epithelial ovarian cancer cells via autophagy-mediated cell cycle arrest } \\
\text { and suppressing the cell cycle-related NF-кB-signaling pathway }\end{array}$ & Li et al. (2018) \\
\hline Dihydroartemisinin & Colorectal & Potentiation of 5-fluorouracil antitumor activity & Yao et al. (2018) \\
\hline Dihydroartemisinin & Colorectal & Induction of iron-dependent endoplasmic reticulum stress & Lu et al. (2011) \\
\hline Dihydroartemisinin & $\begin{array}{l}\text { HeLa cervical } \\
\text { cancer cells }\end{array}$ & Autophagy within cancer cells through Bcl-2 phosphorylation at Ser70 & Wang L. et al. (2019) \\
\hline Dihydroartemisinin & Cervical & Cytotoxic activity against papillomavirus-expressing epithelial cells & Disbrow et al. (2005) \\
\hline Dihydroartemisinin & Esophageal & Inactivating of NF-кB in Eca109 and Ec9706 & Li et al. (2014) \\
\hline Dihydroartemisinin & Esophageal & 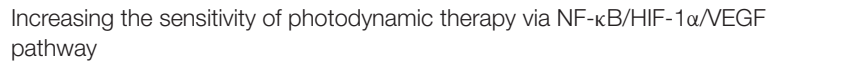 & Li et al. (2018) \\
\hline Dihydroartemisinin & Breast & Inducing apoptosis & Mao et al. (2013) \\
\hline Dihydroartemisinin & Hepatocellular & $\begin{array}{l}\text { Inhibiting proliferation and inducing apoptosis of cancer cell by upregulating tumor } \\
\text { necrosis factor via JNK/NF-кB pathways }\end{array}$ & Wu et al. (2019) \\
\hline Dihydroartemisinin & Ovarian & $\begin{array}{l}\text { Inducing apoptosis and inhibiting proliferation, migration, and invasion in cancer } \\
\text { cells via inhibition of the hedgehog signaling pathway }\end{array}$ & Liu et al. (2018) \\
\hline Dihydroartemisinin & Ovarian & $\begin{array}{l}\text { Inhibiting PDGFR } \alpha \text {-positive cancer cell growth and metastasis through inducing } \\
\text { degradation of PDGFR } \alpha \text { protein }\end{array}$ & Li et al. (2017) \\
\hline Dihydroartemisinin & Ovarian & $\begin{array}{l}\text { Inhibiting cancer cell growth, inducing apoptosis and G2 cell cycle arrest, } \\
\text { decreasing of } \mathrm{Bcl}-\mathrm{xL} \text { and } \mathrm{Bcl}-2 \text {, and increasing of } \mathrm{Bax} \text { and Bad }\end{array}$ & Jiao et al. (2007) \\
\hline Dihydroartemisinin & Various Cancers & Inhibiting angiogenesis & Chen et al. (2003) \\
\hline Dihydroartemisinin & $\begin{array}{l}\text { Cholangiocarcinoma } \\
\text { and } \\
\text { Hepatocarcinoma }\end{array}$ & Expression of TDR1, MDR1, MRP1, MRP2, and MRP3 & Chaijaroenkul et al. (2011) \\
\hline Dihydroartemisinin & Pancreatic & $\begin{array}{l}\text { Inhibiting cell viability, downregulating the expression of proliferating cell nuclear } \\
\text { antigen and cyclin D1, upregulated p } 21 \mathrm{WAF} 1 / \mathrm{CIP} 1 \text {, inducing apoptosis by } \\
\text { reducing the ratio of Bcl-2/Bax and increasing the activation of caspase- } 9\end{array}$ & Chen et al. (2009) \\
\hline Dihydroartemisinin & Pancreatic & Inducing oncosis-like cell death & Du et al. (2010) \\
\hline Dihydroartemisinin & Pancreatic & Inducing cell cycle arrest, apoptosis, and inhibiting of NF-kB signaling & Chen et al. (2010) \\
\hline Dihydroartemisinin & Pancreatic & Inhibiting NF-kB pathway & $\begin{array}{l}\text { Wang et al. (2011); Wang } \\
\text { et al. (2010) }\end{array}$ \\
\hline Dihydroartemisinin & Non-small-cell lung & Suppressing metastasis of cancer via inhibiting NF-kB/GLUT1 axis & Jiang J. et al. (2016) \\
\hline Artemisone & Melanoma & Inhibiting cancer cell growth & Dwivedi et al. (2015) \\
\hline Artemisone & $\begin{array}{l}\text { Breast, Colon, } \\
\text { Melanoma, and } \\
\text { Pancreatic }\end{array}$ & Reducing cell viability and arresting cell cycling & Gravett et al. (2011) \\
\hline Artemether & Gastric & $\begin{array}{l}\text { Increasing of DNA-damage index, inducing necrosis in PG100, inducing both } \\
\text { apoptosis and necrosis in lymphocytes }\end{array}$ & Alcântara et al. (2013) \\
\hline $\begin{array}{l}\text { Artesunic } \\
\text { acid+Thymoquinone }\end{array}$ & Colorectal & Increasing of ROS, and elevating levels of DNA-damage marker $\gamma$-H2AX & Fröhlich et al. (2017) \\
\hline $\begin{array}{l}\text { Anhydro } \\
\text { dihydroartemisinin and } \\
\text { 10-dihydroartemisinyl } \\
\text { acetate }\end{array}$ & Liver/Colon & Antiproliferative and inhibiting the release of BVDV-RNA & Blazquez et al. (2013) \\
\hline $\begin{array}{l}\text { Artemisinin, } \\
\text { Dihydroartemisinin, and } \\
\text { Artesunate }\end{array}$ & Non-small-cell lung & Inhibiting tumorigenesis and tumor metastasis through $\mathrm{Wnt} / \beta$-catenin signaling & Tong et al. (2016) \\
\hline
\end{tabular}


Kapepula et al., 2020; Koshak and Koshak, 2020; Mani et al., 2020; Verma et al., 2020; Williamson and Kerimi, 2020; Belhassan et al., 2021; Hassanipour et al., 2021; Javed et al., 2021; Lyu et al., 2021; Nazrul Islam et al., 2021; Song et al., 2021).

In vitro efficacy of artemisinin-based treatments to combating SARS-CoV-2 has indicated that treatment with artesunate, artemether, A. annua extracts, and artemisinin hindered virus infections of human lung cancer A549-hACE2 cells, VeroE6 cells, and human hepatoma Huh7.5 cells. Among these four treatments, artesunate showed the strongest anti-SARS-CoV-2 activity $(7-12 \mu \mathrm{g} / \mathrm{mL})$, followed by artemether $(53-98 \mu \mathrm{g} / \mathrm{mL})$, A. annua extracts $(83-260 \mu \mathrm{g} / \mathrm{mL})$, and artemisinin (151 to at least $208 \mu \mathrm{g} / \mathrm{mL})$. Collectively, time-of-addition experiments in A549-hACE2 cells displayed that artesunate attacked the virus at the post-entry level (Zhou et al., 2021). In parallel with the previous study, dried-leaf hot-water extracts of $A$. annua cultivars including SAM, BUR, A3, and MED revealed in vitro antiSARS-CoV-2 activity against Alpha, Beta, Gamma, Delta, and Kappa variants of the virus. All cultivars in addition to being potent in combating with original wild type WA1 also showed effective potential against mentioned variants. IC90 and IC50 according to measured artemisinin content ranged from 1.4$25.0 \mu \mathrm{M}$ and 0.3 to $8.4 \mu \mathrm{M}$, respectively. Also, the IC90 and IC50 according to dried-leaf weight ranged from 59.5-160.6 $\mu \mathrm{g}$ DW and 11.0 to $67.7 \mu \mathrm{g}$ DW, respectively (Nair et al., 2022). Alternatively, Artemisia spp. Extracts and COVID-Organics drink produced in Madagascar hindered in vitro SARS-CoV-2 and Feline coronavirus (FcoV) infections at concentrations that did not influence cell efficacy and viability (Nie et al., 2021).

In another successful in vitro study, six monomer compounds including artesunate, artemether, arteannuin $\mathrm{B}$, andrographolide, licochalcone $\mathrm{B}$, and echinatin exerted high anti-SARS-CoV-2 and anti-GX_P2V (pangolin coronavirus) activity (Hu et al., 2021). In addition to the mentioned monomers, it is noteworthy that the quinoline like artemisinins has shown strong anti-SARSCoV-2 activity (Firestone et al., 2021). Also, the anti-SARS-CoV2 activity of nine artemisinin-based compounds experimented in vitro. Results highlighted that arteannuin $\mathrm{B}$, artesunate, and dihydroartemisinin are the most potent agents in inhibiting virus activity. Also, several artemisinins decreased the generating of the virus nucleocapsid $(\mathrm{N})$ proteins in a dose-dependent manner. It can be concluded that targeting $\mathrm{N}$ proteins can be considered as one of the possible options to control viral infection. On the other hand, both lumefantrine and arteannuin B suppressed viral infection following SARS-CoV-2 entry toward the host cells (Cao et al., 2020). In addition to artemisinins monotherapy, in vitro inhibition of SARS-CoV-2 replication by artemisininbased combination therapies (ACTs) in African experimental society indicated that the artesunate-mefloquine exerted high anti-SARS-CoV-2 activity with $\%$ inhibition of $72.1 \pm 18.3 \%$. Also, other ACTs including artesunate-pyronaridine, artesunateamodiaquine, dihydroartemisinin-piperaquine, and artemetherlumefantrine displayed the same range of inhibition (27.1 to $34.1 \%$ ) (Gendrot et al., 2020). Along with in vitro studies of ACTs, molecular docking studies have also demonstrated the anti-SARS-CoV-2 activity of artemisinin-thymoquinone hybrids against the main protease of the virus (de Oliveira et al., 2021).

\section{Molecular Modes of Action of Artemisinins in Combating COVID-19 Blocking Receptor Binding of Spike Protein to Host Cell Surface}

While extracts from medicinal plants may show some preliminary efficacy in small scale clinical trials (Dong et al., 2020; reviewed in Orege et al., 2021), these do not clarify where the activity is coming from. For instance, the antiviral and immunomodulation effects of Artemisia spp. Extracts, as recently been reviewed (Kshirsagar and Rao, 2021), may not only be due to artemisinins, but also from other potential bioactive compounds like flavonoids, mono- and sesqui-terpenes or tannins in these extracts (Kshirsagar and Rao, 2021). To address efficiency and potential harmful side effects of plant extracts, a more detailed knowledge on the molecular mode of action of individual bioactive molecules is needed (Cheong et al., 2020; Guastalegname and Vallone, 2020). Studies indicate that artesunate, dihydroartemisinin, and artemisinin may act at the cell surface by inhibition of the binding of the SARS-CoV-2 spike protein to cell surface receptors, thus potentially preventing both endocytosis of the virus and activation of the NF- $\kappa \mathrm{B}$ signaling pathway (Gendrot et al., 2020; Rolta et al., 2020; Sehailia and Chemat, 2020; Uckun et al., 2021).

However, molecular docking studies indicate that artemisinins may also bind to coronavirus-host proteins such as E protein, helicase protein, $\mathrm{N}$ protein, $3 \mathrm{CL}^{\mathrm{PRO}}, \mathrm{S}$ protein, nonstructural protein 3 (nsp3), nsp10, nsp14, nsp15, cathepsin-L, and glucoseregulated protein 78 receptor (Fuzimoto, 2021; Ribaudo et al., 2021) and part of the biological activity of artemisinin against COVID-19 may thus also be partially based on inhibiting the function of these viral proteins.

\section{Preventing Cytokine Storm by Inhibiting IKK}

In addition, artemisinin/and or artesunate may limit CS by inhibiting IKK and thus over-active NF- $\mathrm{B}$ signaling, or it may inhibit the transcriptional activity of $\mathrm{p} 50 / \mathrm{p} 65$, released by NF$\kappa \mathrm{B}$ signaling (see GRAPHICAL ABSTRACT). While preliminary studies with artemisinins look promising, researchers have warned that the potential of artemisinins in combating COVID19 requires further clinical research (Uzun and Toptas, 2020; Krishna et al., 2021).

\section{Artemisinins-Related Clinical Trials in Combating COVID-19}

A total of 16 trials with Artemisia spp. Extract, artemisinins, and ACTs have been registered in the US National Library of Medicine ${ }^{1}$ with clinical trial IDs: NCT04530617, NCT04306497, NCT04701606, NCT04695197, NCT04475107, NCT04532931, NCT04374019, NCT05084911, NCT04502342, NCT04801017, NCT04374084, NCT05004753, NCT04387240, NCT04553705, NCT04802382, NCT04382040, and 3 trials in Chinese Clinical Trial Registry (ChiCTR) database ${ }^{2}$ with IDs: ChiCTR2000033049, ChiCTR2000032915, and

\footnotetext{
${ }^{1}$ https://clinicaltrials.gov/

${ }^{2}$ https://www.chictr.org.cn/
} 
ChiCTR2000030082 (suspended by the investigator) to combat SARS-CoV-2 infection.

Until December 2021, only one trial registered in https: //clinicaltrials.gov/ has been terminated with ID number: NCT04530617. Preliminary results from this study indicate that the agents such as A. annua and Camostat mesilate may help reduce the number of hospitalized patients and that the use of artemisinin-piperaquine for treatment of COVID-19 is safe (Li et al., 2020). Therefore, the World Health Organization (WHO) has initiated clinical trials on three promising candidate drugs, including artesunate, to evaluate the anti-inflammatory activity against SARS-CoV-2 (Solidarity Trial PLUS is registered at: ISRCTN83971151). As new mutations occur in the SARSCoV-2, resulting in new variants including Alpha, Beta, Gamma,
Delta, Kappa, and Omicron, combating potential downstream effects of COVID-19 infections remains an important aspect of dealing with the ongoing pandemic, especially when this virus has become endemic.

\section{NATURAL ARTEMISININ PRODUCTION: LOW YIELD AND ALTERNATIVES TO BOOST PRODUCTION}

Artemisinin is produced in glandular trichomes in the leaves and ovary of the A. annua (Wang et al., 2016). Both the specificity of artemisinin biosynthesis occurring in GTs and the fact that GTs represent about $2 \%$ of plant total weight put a

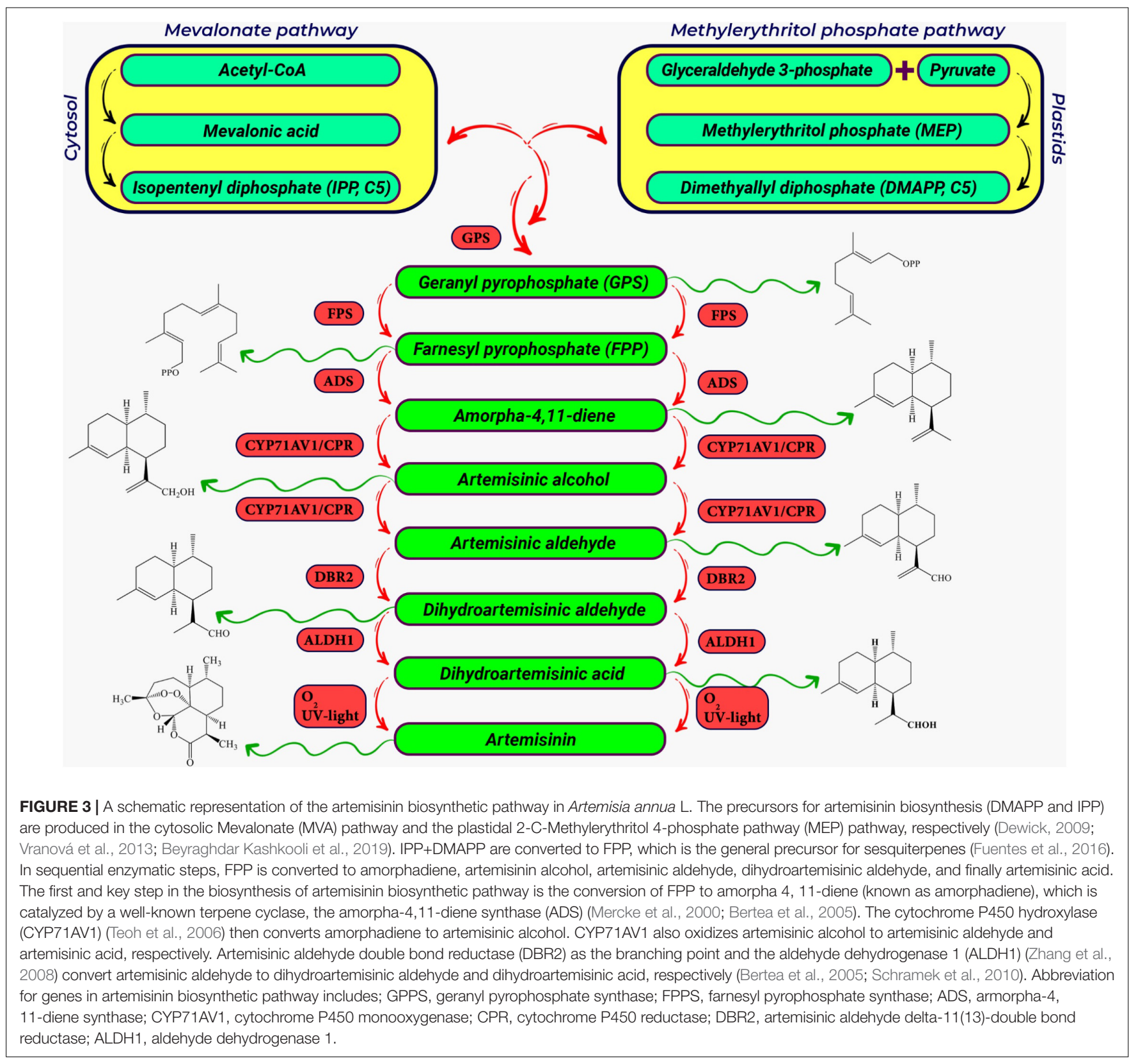


limit to the bulk production of artemisinin in planta (Judd et al., 2019). The different steps in artemisinin production are shown in Figure 3. The end-product of the enzymatic pathway (dihydroartemisinic acid) is presumably toxic to the plant cell and is therefore exported over the plasma membrane and the cell wall to a subcuticular space where it is converted non-enzymatically by light (UV) to artemisinin (Wang et al., 2016). In parallel, artemisinic acid, another end-product of the enzymatic pathway may also be exported from the cell, and extracellularly converted to arteannuin B. Typical yield of artemisinin from the Artemisia annua plant is 0.6 to $1.2 \%$ but may go up to $2 \%$ based on plant dry weight (Zhang et al., 2008). However, such yield is low and far from the potential world's demand (Judd et al., 2019). Current supplies of artemisinin are already limiting to treat people for malaria in a cost-effective way, so use in treating the disease of pandemic proportions like COVID-19 will need new approaches to artemisinin production. Several methods have been proposed to increase artemisinin production so far which are treatments impacting $A$. annua cultivation and physiology and breeding approaches to increase artemisinin yield, engineering artemisinin biosynthetic and transport pathway in the native A. annua plants, and engineering of heterologous (plant and microorganism) systems via ectopic expression of the biosynthetic pathway (Lei et al., 2011; Liu et al., 2011; Parshikov et al., 2012; Fuentes et al., 2016; Kiani et al., 2016; Ikram and Simonsen, 2017; Carqueijeiro et al., 2020).

\section{TREATMENTS IMPACTING ARTEMISININ CONTENT in Artemisia annua}

Thanks to targeted breeding programs different cultivars of A. annua can be grown in a wide range of climate conditions (temperate, cold temperate, subtropical, and Mediterranean) (Ferreira et al., 2005). However, the content and composition of secondary metabolites in A. annua plants are determined by numerous interacting factors: geographical conditions, harvesting time, agricultural practices (e.g., fertilization, irrigation, density per unit area) and post-harvest conditions (Mert et al., 2002; Jelodar et al., 2014). Conventional manipulations of the $A$. annua plant that may enhance artemisinin production are discussed below and summarized in Figure 4 .

\section{Nutrient Manipulations}

In addition to genetic factors, the artemisinin yield can be influenced by environmental conditions and field management practices (Charles et al., 1991). Furthermore, the use of fertilizer compounds can also affect the artemisinin content. As studies have shown, manure and chemical fertilizers are effective in the production of secondary metabolites by improving the photosynthetic rate and carbon production (Jha et al., 2011). Numerous reports have considered the use of nitrogen (N) fertilizer to be somewhat effective in increasing the artemisinin content (Ferreira et al., 2005; Davies et al., 2009; Aftab et al., 2011). In addition to the important role of macronutrients in increasing the artemisinin production in Artemisia plants, studies showed that the deficiency of micronutrients (iron, copper, zinc, and barium) also plays a significant role in reducing the artemisinin content (Srivastava and Sharma, 1990).

\section{Biotic Elicitors}

Similarly, the use of elicitors in plants increases the accumulation of secondary metabolites (Zhao et al., 2005). For instance, the elicitor of Penicillium chrysogenum extract has increased (up to double) the production of artemisinin in hairy roots of A. annua (Liu et al., 1999). Additionally, the application of chitosan or of the arbuscular mycorrhizal species Rhizophagus intraradices (as elicitor) was able to increase the content of dihydroartemisinic acid and artemisinin in Artemisia plants (Lei et al., 2011; Mandal et al., 2014). Since the response to these biotic factors often involves the phytohormone jasmonic acid (JA), the effect of these factors on artemisinin content could be due to activated JA signaling.

\section{Plant Breeding}

The main breeding goals of $A$. annua are the improvement of artemisinin production by increasing the yield potential of leaves, proliferate the number of shoots, and raising the total number of glandular trichomes per plant (Graham et al., 2010; Jelodar et al., 2014). Selection through germplasm and genetic modification can be considered as basic strategies for the improvement of artemisinin production in A. annua (Charles et al., 1991; Xie et al., 2016). A very common breeding technique to increase the secondary metabolites is the manipulation of the ploidy levels in plants (Weathers, 2003). The production of artificial polyploids as a plant breeding strategy has made it possible to develop new and improved cultivars (Iannicelli et al., 2020). In this regard, the application of ploidy manipulation techniques has successfully increased the artemisinin production in A. annua. Reports indicate that the amount of artemisinin in tetraploid plants has increased up to $56 \%$ compared to diploid plants. Alternatively, induced mutation using chemicals such as sodium azide $\left(\mathrm{NaN}_{3}\right)$ and ethyl methane sulfonate (EMS) was effective in increasing the artemisinin biosynthesis in native plant (AlQurainy and Khan, 2010; Leow et al., 2020).

\section{Enhancing Glandular Trichomes}

In some plant species, the production of some glandular type trichomes is enhanced by JA treatment (Chen et al., 2018) or UVB light (Yan et al., 2012). Indeed, the artemisinin content of A. annua is enhanced under the UV treatment at a dosage of 150 gray irradiation (Raymond et al., 2015) and UV-B radiation at $1.44 \mathrm{~kJ} \mathrm{~m}^{-2} \mathrm{~d}^{-1}$ (Pandey and Pandey-Rai, 2014) respectively. This could be due to both an effect on glandular trichome density and enhanced conversion of artemisinic aldehyde to artemisinin.

\section{Plant Growth Regulators}

Various agricultural practices use plant growth regulators (PGRs) to improve artemisinin production. For example, the treatment of $A$. annua with Salicylic acid increases plant growth, leading to higher biomass (Aftab et al., 2010), altered plant morphology, artemisinin content and composition (Ma et al., 2009). Other 

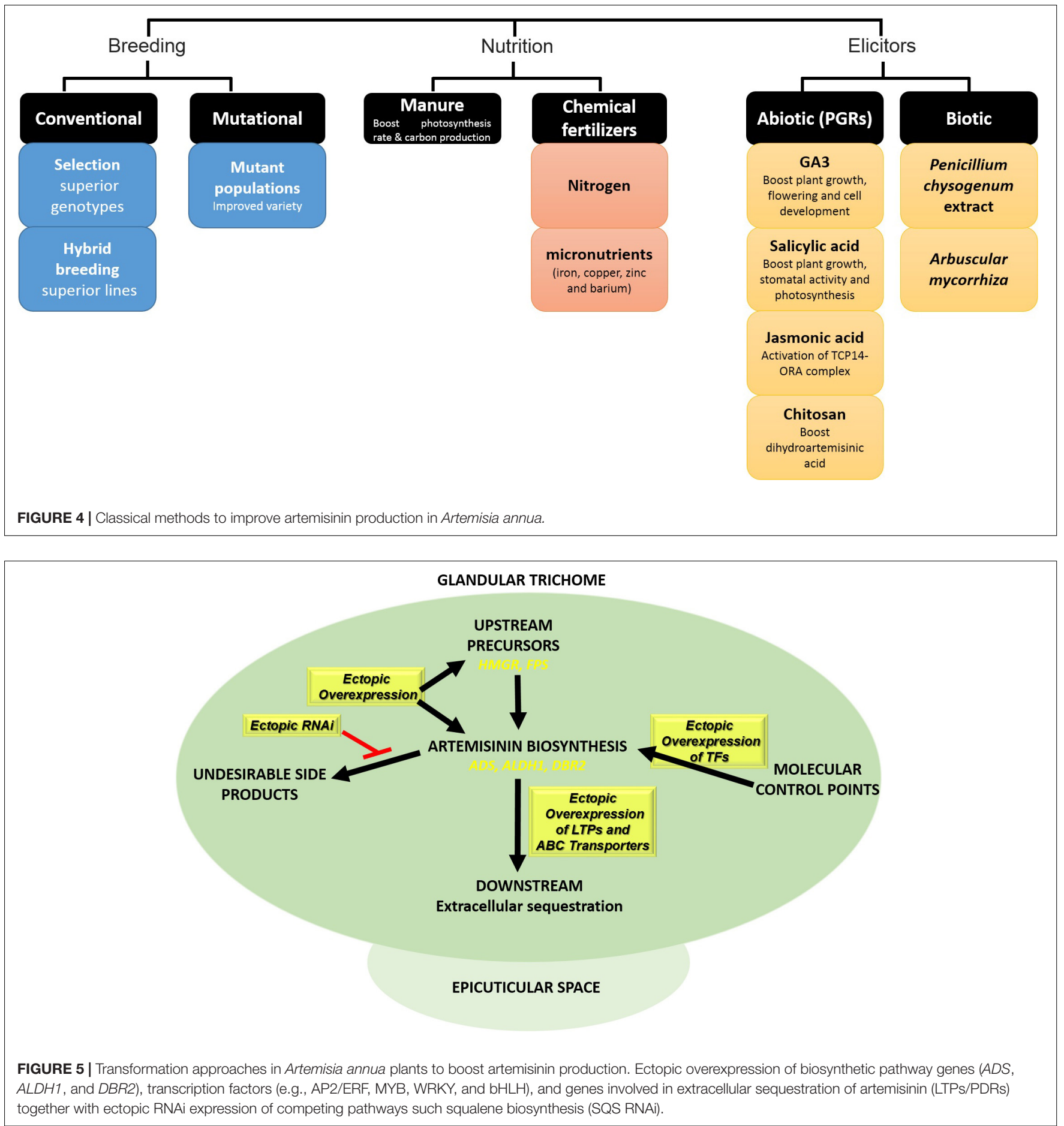

studies have shown that PGR GA 3 (Weathers et al., 2005; Zhang et al., 2005; Aftab et al., 2011) and JA can also increase the artemisinin content of A. annua (Zhou and Memelink, 2016). JA has been shown to boost artemisinin biosynthesis via the releasing of repressors of transcription factor TCP14-ORA at the promoters of double bond reductase $2(D B R)$ and aldehyde dehydrogenase $1(A D H 1)$, two key genes in the artemisinin biosynthetic pathway (see Figure 3; Ma et al., 2018).

\section{BIOENGINEERING OF ARTEMISININ PRODUCTION IN Artemisia annua}

Metabolic engineering may be used to improve the production of artemisinin in A. annua itself but is hampered by the difficulties in efficient transformation and regeneration of $A$. annua plants. Alternatively, the genes that have been isolated from $A$. annua that are involved in artemisinin production may be expressed in 
TABLE 2 | Introducing artemisinin (ART) pathway genes in Artemisia annua L. to improve the ART production using different strategies.

\begin{tabular}{|c|c|c|c|}
\hline & Expression type & Yield & References \\
\hline Artemisia annua L. & Overexpression of $H M G R$ and $A D S$ & $1.73 \mathrm{mg} / \mathrm{g}$ DW & Alam and Abdin (2011) \\
\hline Artemisia annua L. & Overexpression of CYP71AV1 and CPR & $0.98 \pm 0.18 \mathrm{mg} / \mathrm{g}$ & Shen et al. (2012) \\
\hline Artemisia annua L. & Overexpression of FPS,CYP71AV1 and CPR & $2.9 \mathrm{mg} / \mathrm{g} \mathrm{FW}$ & Chen et al. (2013) \\
\hline Artemisia annua L. & Overexpression of FPS & $1.3 \% \mathrm{DW}$ & Banyai et al. (2010) \\
\hline Artemisia annua L. & Overexpression of HMGR & $0.386 \pm 0.0332 \mathrm{mg} / \mathrm{g} \mathrm{DW}$ & Aquil et al. (2009) \\
\hline Artemisia annua L. & Suppressing the expression of SQS & $31.4 \mathrm{mg} / \mathrm{g}$ DW & Zhang et al. (2009) \\
\hline Artemisia annua L. & Overexpression of AaWRKY1 & $\geq 144 \mathrm{mg} / \mathrm{g} \mathrm{DW}$ & Jiang W. et al. (2016) \\
\hline Artemisia annua L. & Overexpression of $D B R 2$ & $1.5-2.14 \mathrm{mg} / \mathrm{g} \mathrm{DW}$ & Yuan et al. (2015) \\
\hline
\end{tabular}

TABLE 3 | Introducing artemisinin (ART) pathway genes in planta to improve the ART production using different strategies.

\begin{tabular}{|c|c|c|c|}
\hline & Expression type & Yield & References \\
\hline Nicotiana benthamiana & Transient expression of ART precursors' genes & $0.000220347 \mathrm{mg} / \mathrm{g} \mathrm{FW}$ & Ting et al. (2013) \\
\hline Nicotiana benthamiana & Expression of $A D S$ & $2 e-7-1.7 e-6 m g / g ~ F W$ & Wallaart et al. (2001) \\
\hline Nicotiana benthamiana & Stable transformation of $A D S$ & 0.00048-0.00094 mg ART/g DW & Farhi et al. (2011) \\
\hline Nicotiana benthamiana & Stable transformation of $m t A D S$ & 0.005-0.0068 mg ART/g DW & Farhi et al. (2011) \\
\hline Nicotiana benthamiana & Stable transformation of $A D S, C Y P 71 A V 1$, and $D B R 2$ & $\begin{array}{l}\mathrm{AD}:>0.004 \mathrm{mg} / \mathrm{g} \mathrm{FW} \text {; AA: }>0.0005 \mathrm{mg} / \mathrm{g} \mathrm{FW} \\
\mathrm{DA}:>0.0015 \mathrm{mg} / \mathrm{g} \mathrm{FW}\end{array}$ & Zhang et al. (2011) \\
\hline Nicotiana benthamiana & Stable transformation of ART B.P. genes & $0.3-0.8 \mathrm{mg} / \mathrm{g} \mathrm{DW}$ & Malhotra et al. (2016) \\
\hline Nicotiana benthamiana & Transient expression of ART B.P. genes & $0.0395 \mathrm{mg} / \mathrm{g} \mathrm{FW}$ & van Herpen et al. (2010) \\
\hline Physcomitrella patens & Stable transformation of ART B.P. genes & $0.21 \mathrm{mg} / \mathrm{g} \mathrm{DW}$ & Ikram et al. (2017) \\
\hline
\end{tabular}

SPG, Stable Plastid Genome; FW, Fresh Weight; DW, Dry Weight; AD, Amorphadiene; AA, Artemisinic alcohol; DA, Dihydroartemisinic alcohol; ART B.P., Artemisinin biosynthetic pathway. All units are converted to milligram per gram $(\mathrm{mg} / \mathrm{g})$.

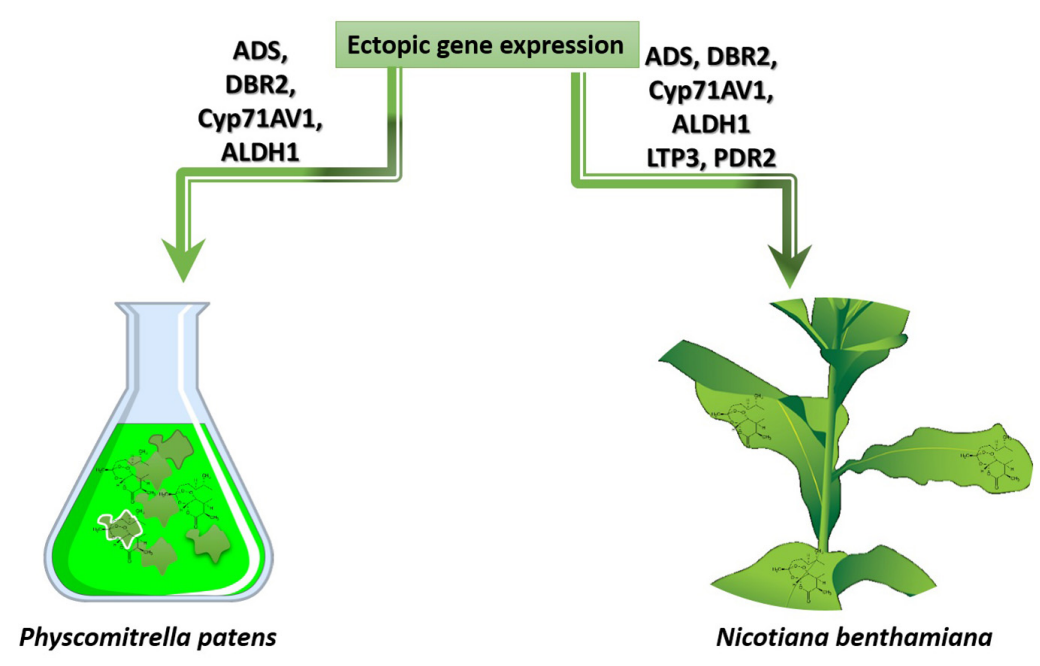

FIGURE 6 | Heterologous overexpression of genes from artemisinin biosynthetic pathway in the host plants N. benthamiana and P. patens.

a heterologous host that is easier to transform and grow (Covello, 2008; Ma et al., 2015; Xie et al., 2016; Lv et al., 2017; Ikram et al., 2019). Options to manipulate artemisinin production in $A$. annua are briefly discussed below and summarized in Figure 5. The yield effects of the different transformation efforts of $A$. annua are summarized in Table 2.

(1) Artemisia annua has been transformed with Agrobacterium genes that affect endogenous plant hormone levels (rol $A B C$ or ipt), resulting in mild to up to 9 times higher artemisinin levels compared to untransformed (or empty vector transformed) control plants (Sa et al., 2001; Bulgakov, 2008; Dilshad et al., 2015; Kiani et al., 2016).

(2) Other transformation strategies are aimed at boosting precursors, either by boosting flux through the Mevalonate pathway by ectopic expression of 3-hydroxy-3-methylglutaryl-CoA reductase (HMGR) or 
TABLE 4 | De novo production of ART precursor via synthetic biology.

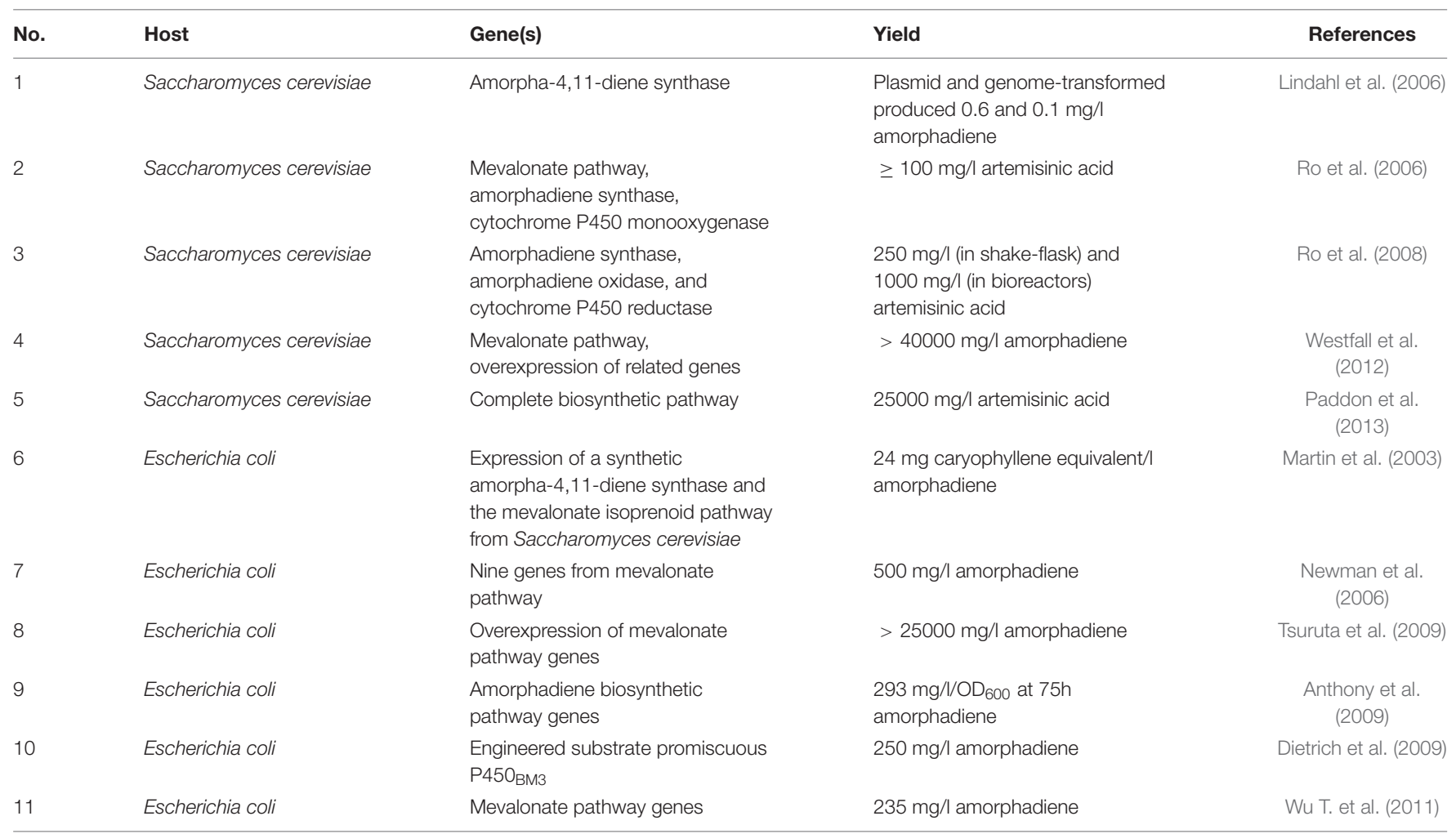

All units are converted to milligram per liter (mg/l).

by blocking unwanted side reactions that drain from the precursor pool (e.g., Squalene synthase (SQS), that diverts FPP to squalene) (Liao et al., 2016). Ectopic expression of $H M G R$ in A. annua can boost artemisinin production (Aquil et al., 2009; Nafis et al., 2011; Ma et al., 2017), while also suppression of $S Q S$ can increase artemisinin levels (Paradise et al., 2008; Yang et al., 2008; Zhang et al., 2009; Table 2 and Figure 5).

(3) Transformation approaches may also be aimed at boosting flux through the artemisinin biosynthetic pathway itself through overexpression of biosynthesis genes. Ectopic overexpression of farnesyl pyrophosphate synthase (FPS) alone or FPS with CYP71AV1 and CPR, increased artemisinin levels in transgenic plants (Table 2; Chen et al., 2000, 2013; Han et al., 2016; Banyai et al., 2010; Wani et al., 2021). In another study, upregulated expression of HMGR, FPS, ADS, Aldh1, and ADS in A. annua increased artemisinin level $39-56 \%$ fold (Lin et al., 2011; Figure 5).

(4) The expression of endogenous biosynthesis genes may also be boosted by ectopic overexpression of relevant transcription factors (TF), provided expression of such TF is limiting for transcription of target genes. Multiple TFs (AP2/ERFs, WRKYs, bHLH, MYCs) have been identified in the regulation of endogenous artemisinin biosynthesis genes (Verpoorte and Memelink, 2002; Yang et al., 2012; Shen et al., 2016; Lv et al., 2017), but not all of these have been tested for stable transformation of A. annua.
However, ectopic expression of WRKY does result in higher artemisinin production in A. апnиа (Jiang W. et al., 2016; Table 2 and Figure 5).

(5) The capacity for extracellular accumulation of dihydroartemisinic acid for extra-cellular conversion to dihydroartemisinin may be of importance for the flux through the biosynthetic pathway to prevent feedback inhibition and possible toxic effects of pathway products. Studies in tobacco have shown that $\mathrm{ABC}$-transporter AaPDR2, in concert with specific LTP AaTLP3 may be required for this function (Wang et al., 2016). In the tobacco assay, AaLTP3 and AaPDR2 prevent dihydroartemisinic acid reflux from the apoplast to the cell, resulting in higher artemisinin levels (Wang et al., 2016). However, manipulation of either ABC-transporter or LTP levels in A. annua has not been performed till now. Potentially, overexpression of these proteins could result in enhanced artemisinin production in A. annua (Figure 5).

\section{BIOENGINEERING OF ARTEMISININ IN HETEROLOGOUS PRODUCTION PLATFORMS}

\section{In planta Artemisinin Production}

The genes for artemisinin production have also been expressed in other plants, either by transient expression or by stable 
transformation. To date, in planta artemisinin production has been reported for tobacco (Nicotiana benthamiana) and moss (Physcomitrella patens) (Table 3). Transient expression of genes in $N$. benthamiana leaves is used to characterize gene function and has the advantage that up to 15 genes may be coexpressed at the same time to transiently reconstitute entire biosynthetic pathways (Reed et al., 2017; Carqueijeiro et al., 2020). Reconstruction of the artemisinin biosynthetic pathway by transient co-expression of pathway genes (Wallaart et al., 2001; Zhang et al., 2011; Ting et al., 2013; Wang et al., 2016) or stable transformation with pathway genes (Farhi et al., 2011) resulted in the first ectopic production of artemisinin in another plant species (Table 3). Recently, the stable transformation of the moss (P. patens) with artemisinin pathway genes, demonstrated that this compound may also be produced in much more primitive plant species (Ikram et al., 2017; Table 3 and Figure 6). As a plant-based production platform of artemisinin, moss has been shown to have promiscuous substrate recognition which may be a substitute for some artemisinin biosynthetic pathway genes which are not present in for example $N$. benthamiana. Substrate promiscuity of sesquiterpenoids pathway from A. annua and Tanacetum parthenium for individual enzymes or pathways is previously reported (Beyraghdar Kashkooli et al., 2019). Besides, the simple purification step (due to lack of conjugation phenomenon) has been also stated as one of the advantages of this platform compared to the $N$. benthamiana.

\section{Artemisinin Production in Yeast}

Synthetic biology techniques play an important role in the exploration, overproduction, and structure diversification of phytochemicals (Qi et al., 2015; Muhammad et al., 2020; Alam et al., 2021). The full set of artemisinin biosynthesis genes have also been introduced into yeast, resulting in substantial production of dihydroartemisinic acid in fermenters (Immethun et al., 2013; Paddon et al., 2013; Tang et al., 2014; Table 4). This dihydroartemisinic acid can subsequently photo-chemically be converted to (dihydro)artemisinin (Paddon and Keasling, 2014). Some of the issues that play a role in the potential boosting of artemisinin production in A. annua as discussed above, also play

\section{REFERENCES}

Aftab, T., Khan, M. M. A., Idrees, M., Naeem, M., and Moinuddin. (2011). Optimizing nitrogen levels combined with gibberellic acid for enhanced yield, photosynthetic attributes, enzyme activities, and artemisinin content of Artemisia annua. Front. Agric. China 5:51-59. doi: 10.1007/s11703-011-1065-7

Aftab, T., Masroor, M., Khan, A., Idrees, M., Naeem, M., and Moinuddin. (2010). Salicylic acid acts as potent enhancer of growth, photosynthesis and artemisinin production in Artemisia annua L. J. Crop Sci. Biotechnol. 13, 183-188. doi: 10.1007/s12892-010-0040-3

Alam, K., Hao, J., Zhang, Y., and Li, A. (2021). Synthetic biology-inspired strategies and tools for engineering of microbial natural product biosynthetic pathways. Biotechnol. Adv. 49:107759. doi: 10.1016/j.biotechadv.2021.107759

Alam, P., and Abdin, M. Z. (2011). Over-expression of HMG-CoA reductase and amorpha-4,11-diene synthase genes in Artemisia annua L. and its influence on artemisinin content. Plant Cell Rep. 30, 1919-1928. doi: 10.1007/s00299-0111099-6

Alcântara, D. D. F. Á, Ribeiro, H. F., Cardoso, P. C., dos, S., Araújo, T. M. T., Burbano, R. R., et al. (2013). In vitro evaluation of the cytotoxic and genotoxic a role in boosting artemisinin production in heterologous hosts. For instance, high activity of HMGR is also important for the ectopic production of artemisinin in yeast (Pitera et al., 2007; Ye and Bhatia, 2012; Tang et al., 2014) (Table 4).

\section{CONCLUSION}

Whether artemisinin can be used to not only combat malaria, but also other diseases, including those acting on a pandemic scale, will very much depend on further validation of the efficacy of artemisinin in these other diseases and on how this compound can cost-effectively be made available to the community. Multiple and complementary approaches may be necessary to boost synthesis capacity, varying from the transformation of $A$. annua itself to boost artemisinin yield, to investment into heterologous production platforms that may be easier to scale up. At the same time, we should not ignore the lessons learned from monotherapy in combating disease, as this may result in the emergence of artemisinin-resistance, as currently happening for malaria. Therefore, both for malaria, as for the potential of artemisinin in combating COVID-19 and other viral infections ACTs or triple artemisinin-based combination therapies (TACTs) may be required to prevent the rise of artemisinin resistant disease variants.

\section{AUTHOR CONTRIBUTIONS}

ABK conceptualized the review. KF-K, AR, AB, ARK, and $A B K$ wrote the manuscript. $A B K, A R K$, and $A B$ reviewed the manuscript. KF-K, AR, and $\mathrm{ABK}$ did the figures visualization. All authors contributed to the article and approved the submitted version.

\section{ACKNOWLEDGMENTS}

We would like to thank Tarbiat Modares University.

effects of artemether, an antimalarial drug, in a gastric cancer cell line (PG100). J. Appl. Toxicol. 33, 151-156. doi: 10.1002/jat.1734

Aldieri, E., Atragene, D., Bergandi, L., Riganti, C., Costamagna, C., Bosia, A., et al. (2003). Artemisinin inhibits inducible nitric oxide synthase and nuclear factor NF-kB activation. FEBS Lett. 552, 141-144. doi: 10.1016/S0014-5793(03)00 905-0

Al-Qurainy, F., and Khan, S. (2010). Mutational approach for enhancement of artemisinin in Artemisia annua. J. Med. Plants Res. 4, 1714-1726. doi: 10.1016/ j.jbiotec.2010.09.708

Anfosso, L., Efferth, T., Albini, A., and Pfeffer, U. (2006). Microarray expression profiles of angiogenesis-related genes predict tumor cell response to artemisinins. Pharmacogenomics J. 6, 269-278. doi: 10.1038/sj.tpj.6500371

Anthony, J. R., Anthony, L. C., Nowroozi, F., Kwon, G., Newman, J. D., and Keasling, J. D. (2009). Optimization of the mevalonate-based isoprenoid biosynthetic pathway in Escherichia coli for production of the anti-malarial drug precursor amorpha-4,11-diene. Metab. Eng. 11, 13-19. doi: 10.1016/j.ymben. 2008.07.007

Antoine, T., Fisher, N., Amewu, R., O’Neill, P. M., Ward, S. A., and Biagini, G. A. (2014). Rapid kill of malaria parasites by artemisinin and semi-synthetic 
endoperoxides involves ROS-dependent depolarization of the membrane potential. J. Antimicrob. Chemother. 69, 1005-1016. doi: 10.1093/jac/dkt486

Aquil, S., Husaini, A. M., Abdin, M. Z., and Rather, G. M. (2009). Overexpression of the HMG-CoA reductase gene leads to enhanced artemisinin biosynthesis in transgenic Artemisia annua plants. Planta Med. 75, 1453-1458. doi: 10.1055/s0029-1185775

Krishna, S., Augustin, Y., Wang, J., Xu, C., Staines, H. M., Platteeuw, H., et al. (2021). Repurposing antimalarials to tackle the COVID-19 pandemic. Trends Parasitol. 37, 8-11. doi: 10.1016/j.pt.2020.10.00

Bahrami, M., Kamalinejad, M., Latifi, S. A., Seif, F., and Dadmehr, M. (2020). Cytokine storm in COVID-19 and parthenolide: preclinical evidence. Phyther. Res. 34, 2429-2430. doi: 10.1002/ptr.6776

Bailly, C., and Vergoten, G. (2020). Glycyrrhizin: an alternative drug for the treatment of COVID-19 infection and the associated respiratory syndrome? Pharmacol. Ther. 214:107618. doi: 10.1016/j.pharmthera.2020.107618

Banyai, W., Kirdmanee, C., Mii, M., and Supaibulwatana, K. (2010). Overexpression of farnesyl pyrophosphate synthase (FPS) gene affected artemisinin content and growth of Artemisia annua L. Plant Cell. Tissue Organ Cult. 103, 255-265. doi: 10.1007/s11240-010-9775-8

Beccafico, S., Morozzi, G., Marchetti, M. C., Riccardi, C., Sidoni, A., Donato, R., et al. (2015). Artesunate induces ROS- and p38 MAPK-mediated apoptosis and counteracts tumor growth in vivo in embryonal rhabdomyosarcoma cells. Carcinogenesis 36, 1071-1083. doi: 10.1093/carcin/bgv098

Belhassan, A., Zaki, H., Chtita, S., Alaqarbeh, M., Alsakhen, N., Benlyas, M., et al. (2021). Camphor, artemisinin and sumac phytochemicals as inhibitors against COVID-19: computational approach. Comput. Biol. Med. 136:104758. doi: 10.1016/j.compbiomed.2021.104758

Berdelle, N., Nikolova, T., Quiros, S., Efferth, T., and Kaina, B. (2011). Artesunate induces oxidative DNA damage, sustained DNA double-strand breaks, and the ATM/ATR damage response in cancer cells. Mol. Cancer Ther. 10, 2224-2233. doi: 10.1158/1535-7163.MCT-11-0534

Bertea, C. M., Freije, J. R., Van Der Woude, H., Verstappen, F. W. A., Perk, L., Marquez, V., et al. (2005). Identification of intermediates and enzymes involved in the early steps of artemisinin biosynthesis in Artemisia annua. Planta Med. 71, 40-47. doi: 10.1055/s-2005-837749

Beyraghdar Kashkooli, A., van der Krol, A. R., and Bouwmeester, H. (2018). "Terpenoid biosynthesis in plants," in Flavour Sci., Verlag der Technischen Universität Graz, eds B. Siegmund and E. Leitner 3-11. doi: 10.3217/978-385125-593-5-1

Beyraghdar Kashkooli, A., van der Krol, A. R., Rabe, P., Dickschat, J. S., and Bouwmeester, H. (2019). Substrate promiscuity of enzymes from the sesquiterpene biosynthetic pathways from Artemisia annua and Tanacetum parthenium allows for novel combinatorial sesquiterpene production. Metab. Eng. 54, 12-23. doi: 10.1016/j.ymben.2019.01.007

Blazquez, A. G., Fernandez-Dolon, M., Sanchez-Vicente, L., Maestre, A. D., Gomez-San Miguel, A. B., Alvarez, M., et al. (2013). Novel artemisinin derivatives with potential usefulness against liver/colon cancer and viral hepatitis. Bioorganic Med. Chem. 21, 4432-4441. doi: 10.1016/j.bmc.2013.04. 059

Bridgford, J. L., Xie, S. C., Cobbold, S. A., Pasaje, C. F. A., Herrmann, S., Yang, T., et al. (2018). Artemisinin kills malaria parasites by damaging proteins and inhibiting the proteasome. Nat. Commun. 9, 1-9. doi: 10.1038/s41467-01806221- 1

Bulgakov, V. P. (2008). Functions of rol genes in plant secondary metabolism. Biotechnol. Adv. 26, 318-324. doi: 10.1016/j.biotechadv.2008.03.001

Cao, R., Hu, H., Li, Y., Wang, X., Xu, M., Liu, J., et al. (2020). Anti-SARS-CoV-2 potential of artemisinins in vitro. ACS Infect. Dis. 6, 2524-2531. doi: 10.1021/ ACSINFECDIS.0C00522

Cao, Y., Feng, Y. H., Gao, L. W., Li, X. Y., Jin, Q. X., Wang, Y. Y., et al. (2019). Artemisinin enhances the anti-tumor immune response in $4 \mathrm{~T} 1$ breast cancer cells in vitro and in vivo. Int. Immunopharmacol. 70, 110-116. doi: 10.1016/j. intimp.2019.01.041

Carqueijeiro, I., Langley, C., Grzech, D., Koudounas, K., Papon, N., O’Connor, S. E., et al. (2020). Beyond the semi-synthetic artemisinin: metabolic engineering of plant-derived anti-cancer drugs. Curr. Opin. Biotechnol. 65, 17-24. doi: 10.1016/j.copbio.2019.11.017

Chaijaroenkul, W., Viyanant, V., Mahavorasirikul, W., and Na-Bangchang, K. (2011). Cytotoxic activity of artemisinin derivatives against cholangiocarcinoma (CL-6) and hepatocarcinoma (Hep-G2) cell lines. Asian Pacific J. Cancer Prev. 12, 55-59.

Charles, D. J., Cebert, E., and Simon, J. E. (1991). Characterization of the essential oil of Artemisia annua L. J. Essent. Oil Res. 3, 33-39. doi: 10.1080/10412905. 1991.9697903

Chen, C., Chen, K., Feng, Z., Wen, X., and Sun, H. (2019). Synergistic antitumor activity of artesunate and HDAC inhibitors through elevating heme synthesis via synergistic upregulation of ALAS1 expression. Acta Pharm. Sin. B 9, 937951. doi: 10.1016/j.apsb.2019.05.001

Chen, D. H., Ye, H. C., and Li, G. F. (2000). Expression of a chimeric farnesyl diphosphate synthase gene in Artemisia annua L. transgenic plants via Agrobacterium tumefaciens-mediated transformation. Plant Sci. 155, 179-185. doi: 10.1016/S0168-9452(00)00217-X

Chen, G., Klinkhamer, P. G. L., Escobar-Bravo, R., and Leiss, K. A. (2018). Type VI glandular trichome density and their derived volatiles are differently induced by jasmonic acid in developing and fully developed tomato leaves: implications for thrips resistance. Plant Sci. 276, 87-98. doi: 10.1016/j.plantsci.2018. 08.007

Chen, H., Sun, B., Pan, S., Jiang, H., and Sun, X. (2009). Dihydroartemisinin inhibits growth of pancreatic cancer cells in vitro and in vivo. Anticancer. Drugs 20, 131-140. doi: 10.1097/CAD.0b013e3283212ade

Chen, H., Sun, B., Wang, S., Pan, S., Gao, Y., Bai, X., et al. (2010). Growth inhibitory effects of dihydroartemisinin on pancreatic cancer cells: involvement of cell cycle arrest and inactivation of nuclear factor-кB. J. Cancer Res. Clin. Oncol. 136, 897-903. doi: 10.1007/s00432-009-0731-0

Chen, H. H., Zhou, H. J., and Fang, X. (2003). Inhibition of human cancer cell line growth and human umbilical vein endothelial cell angiogenesis by artemisinin derivatives in vitro. Pharmacol. Res. 48, 231-236. doi: 10.1016/S1043-6618(03) 00107-5

Chen, K., Shou, L. M., Lin, F., Duan, W. M., Wu, M. Y., Xie, X., et al. (2014). Artesunate induces G2/M cell cycle arrest through autophagy induction in breast cancer cells. Anticancer. Drugs 25, 652-662. doi: 10.1097/CAD. 0000000000000089

Chen, X., Wong, Y. K., Lim, T. K., Lim, W. H., Lin, Q., Wang, J., et al. (2017). Artesunate activates the intrinsic apoptosis of HCT116 cells through the suppression of fatty acid synthesis and the NF-кB pathway. Molecules 22:1272. doi: 10.3390/molecules 22081272

Chen, X., Zhang, X. L., Zhang, G. H., and Gao, Y. F. (2019). Artesunate promotes Th1 differentiation from CD4+ T cells to enhance cell apoptosis in ovarian cancer via miR-142. Brazilian J. Med. Biol. Res. 52, 1-8. doi: 10.1590/1414$431 \times 20197992$

Chen, Y., Shen, Q., Wang, Y., Wang, T., Wu, S., Zhang, L., et al. (2013). The stacked over-expression of FPS, CYP71AV1 and CPR genes leads to the increase of artemisinin level in Artemisia annua L. Plant Biotechnol. Rep. 7, 287-295. doi: 10.1007/s11816-012-0262-z

Cheong, D. H. J., Tan, D. W. S., Wong, F. W. S., and Tran, T. (2020). Anti-malarial drug, artemisinin and its derivatives for the treatment of respiratory diseases. Pharmacol. Res. 158:104901. doi: 10.1016/j.phrs.2020.104901

Conti, P., and Younes, A. (2020). Coronavirus COV-19/SARS-CoV-2 affects women less than men: clinical response to viral infection. J. Biol. Regul. Homeost. Agents 34, 339-343. doi: 10.23812/Editorial-Conti-3

Covello, P. S. (2008). Making artemisinin. Phytochemistry 69, 2881-2885. doi: 10.1016/j.phytochem.2008.10.001

Cui, C., Feng, H., Shi, X., Wang, Y., Feng, Z., Liu, J., et al. (2015). Artesunate downregulates immunosuppression from colorectal cancer Colon26 and RKO cells in vitro by decreasing transforming growth factor $\beta 1$ and interleukin10. Int. Immunopharmacol. 27, 110-121. doi: 10.1016/j.intimp.2015. 05.004

D'alessandro, S., Scaccabarozzi, D., Signorini, L., Perego, F., Ilboudo, D. P., Ferrante, P., et al. (2020). The use of antimalarial drugs against viral infection. Microorganisms 8, 1-26. doi: 10.3390/microorganisms8010085

Davies, M. J., Atkinson, C. J., Burns, C., Woolley, J. G., Hipps, N. A., Arroo, R. R. J., et al. (2009). Enhancement of artemisinin concentration and yield in response to optimization of nitrogen and potassium supply to Artemisia annua. Ann. Bot. 104, 315-323. doi: 10.1093/aob/mcp126

de Oliveira, V. M., da Rocha, M. N., Magalhães, E. P., da Silva Mendes, F. R., Marinho, M. M., de Menezes, R. R. P. P. B., et al. (2021). Computational approach towards the design of artemisinin-thymoquinone hybrids against 
main protease of SARS-COV-2. Futur. J. Pharm. Sci. 7, 1-20. doi: 10.1186/ s43094-021-00334-z

Dewick, P. M. (2009). Medicinal Natural Products: A Biosynthetic Approach, 3rd Edn. New York, NY: Wiley.

Dietrich, J. A., Yoshikuni, Y., Fisher, K. J., Woolard, F. X., Ockey, D., McPhee, D. J., et al. (2009). A novel semi-biosynthetic route for artemisinin production using engineered substrate-promiscuous P450BM3. ACS Chem. Biol. 4, 261-267. doi: $10.1021 / \mathrm{cb} 900006 \mathrm{~h}$

Dilshad, E., Cusido, R. M., Palazon, J., Estrada, K. R., Bonfill, M., and Mirza, B. (2015). Enhanced artemisinin yield by expression of rol genes in Artemisia annua. Malar. J. 14, 1-10. doi: 10.1186/s12936-015-0951-5

Disbrow, G. L., Baege, A. C., Kierpiec, K. A., Yuan, H., Centeno, J. A., Thibodeaux, C. A., et al. (2005). Dihydroartemisinin is cytotoxic to papillomavirusexpressing epithelial cells in vitro and in vivo. Cancer Res. 65, 10854-10861. doi: 10.1158/0008-5472.CAN-05-1216

Dong, F., Zhou, X., Li, C., Yan, S., Deng, X., Cao, Z., et al. (2014). Dihydroartemisinin targets VEGFR2 via the NF- $\mathrm{B}$ pathway in endothelial cells to inhibit angiogenesis. Cancer Biol. Ther. 15, 1479-1488. doi: 10.4161/ 15384047.2014.955728

Dong, H. Y., and Wang, Z. F. (2014). Antitumor effects of artesunate on human breast carcinoma MCF-7 cells and IGF-IR expression in nude mice xenografts. Chin. J. Cancer Res. 26, 200-207. doi: 10.3978/j.issn.1000-9604.2014.04.07

Dong, L., Hu, S., and Gao, J. (2020). Discovering drugs to treat coronavirus disease 2019 (COVID-19). Drug Discov. Ther. 14, 58-60. doi: 10.5582/ddt.2020.01012

Du, J. H., Zhang, H., De Ma, Z. J., and Ji, K. M. (2010). Artesunate induces oncosis-like cell death in vitro and has antitumor activity against pancreatic cancer xenografts in vivo. Cancer Chemother. Pharmacol. 65, 895-902. doi: 10.1007/s00280-009-1095-5

Dwivedi, A., Mazumder, A., du Plessis, L., du Preez, J. L., Haynes, R. K., and du Plessis, J. (2015). In vitro anti-cancer effects of artemisone nano-vesicular formulations on melanoma cells. Nanomed. Nanotechnol. Biol. Med. 11, 20412050. doi: 10.1016/j.nano.2015.07.010

Efferth, T. (2018). Beyond malaria: the inhibition of viruses by artemisinin-type compounds. Biotechnol. Adv. 36, 1730-1737. doi: 10.1016/j.biotechadv.2018.01. 001

Efferth, T., Benakis, A., Romero, M. R., Tomicic, M., Rauh, R., Steinbach, D., et al. (2004). Enhancement of cytotoxicity of artemisinins toward cancer cells by ferrous iron. Free Radic. Biol. Med. 37, 998-1009. doi: 10.1016/j.freeradbiomed. 2004.06.023

Efferth, T., Marschall, M., Wang, X., Huong, S.-M., Hauber, I., Olbrich, A., et al. (2002). Antiviral activity of artesunate towards wild-type, recombinant, and ganciclovir-resistant human cytomegaloviruses. J. Mol. Med. 80, 233-242. doi: 10.1007/s00109-001-0300-8

Efferth, T., and Oesch, F. (2021). The immunosuppressive activity of artemisinintype drugs towards inflammatory and autoimmune diseases. Med. Res. Rev. 41, 3023-3061. doi: 10.1002/med.21842

Efferth, T., Romero, M. R., Wolf, D. G., Stamminger, T., Marin, J. J. G., and Marschall, M. (2008). The antiviral activities of artemisinin and artesunate. Clin. Infect. Dis. 47, 804-811. doi: 10.1086/591195

Eling, N., Reuter, L., Hazin, J., Hamacher-Brady, A., and Brady, N. R. (2015). Identification of artesunate as a specific activator of ferroptosis in pancreatic cancer cells. Oncoscience 2, 517-532. doi: 10.18632/oncoscience.160

Farhi, M., Marhevka, E., Ben-Ari, J., Algamas-Dimantov, A., Liang, Z., Zeevi, V., et al. (2011). Generation of the potent anti-malarial drug artemisinin in tobacco. Nat. Biotechnol. 29, 1072-1074. doi: 10.1038/nbt.2054

Fei, Z., Gu, W., Xie, R., Su, H., and Jiang, Y. (2018). Artesunate enhances radiosensitivity of esophageal cancer cells by inhibiting the repair of DNA damage. J. Pharmacol. Sci. 138, 131-137. doi: 10.1016/j.jphs.2018.09.011

Ferreira, J. F. S., Laughlin, J. C., Delabays, N., and de Magalhães, P. M. (2005). Cultivation and genetics of Artemisia annua L. for increased production of the antimalarial artemisinin. Plant Genet. Resour. 3, 206-229. doi: 10.1079/ pgr200585

Firestone, T. M., Oyewole, O. O., Reid, S. P., and Ng, C. L. (2021). Repurposing quinoline and artemisinin antimalarials as therapeutics for SARS-CoV-2: rationale and implications. ACS Pharmacol. Transl. Sci. 4, 613-623. doi: 10. 1021/acsptsci.0c00222

Fröhlich, T., Kiss, A., Wölfling, J., Mernyák, E., Kulmány, ÁE., Minorics, R., et al. (2018). Synthesis of artemisinin-estrogen hybrids highly active against
HCMV, P. falciparum, and cervical and breast Cancer. ACS Med. Chem. Lett. 9, 1128-1133. doi: 10.1021/acsmedchemlett.8b00381

Fröhlich, T., Ndreshkjana, B., Muenzner, J. K., Reiter, C., Hofmeister, E., Mederer, S., et al. (2017). Synthesis of novel hybrids of thymoquinone and artemisinin with hig activity and selectivity against colon cancer. Chem. Med. Chem. 12, 226-234. doi: 10.1002/cmdc.201600594

Fuentes, P., Zhou, F., Erban, A., Karcher, D., Kopka, J., and Bock, R. (2016). A new synthetic biology approach allows transfer of an entire metabolic pathway from a medicinal plant to a biomass crop. Elife 5, 1-26. doi: 10.7554/eLife.13664

Fuzimoto, A. D. (2021). An overview of the anti-SARS-CoV-2 properties of Artemisia annua, its antiviral action, protein-associated mechanisms, and repurposing for COVID-19 treatment. J. Integr. Med. 19, 375-388. doi: 10.1016/ j.joim.2021.07.003

Gendrot, M., Duflot, I., Boxberger, M., Delandre, O., Jardot, P., Le Bideau, M., et al. (2020). Antimalarial artemisinin-based combination therapies (ACT) and COVID-19 in Africa: in vitro inhibition of SARS-CoV-2 replication by mefloquine-artesunate. Int. J. Infect. Dis. 99, 437-440. doi: 10.1016/j.ijid.2020. 08.032

Gong, Y., Gallis, B. M., Goodlett, D. R., Yang, Y., Lu, H., Lacoste, E., et al. (2013). Effects of transferrin conjugates of artemisinin and artemisinin dimer on breast cancer cell lines. Anticancer Res. 33, 123-132.

Graham, L. A., Besser, K., Blumer, S., Branigan, C. A., Czechowski, T., Elias, L., et al. (2010). The genetic map of Artemisia annua L identifies loci affecting yield of the antimalarial drug artemisinin. Science 327, 328-331. doi: 10.1126/science. 1182612

Gravett, A. M., Liu, W. M., Krishna, S., Chan, W. C., Haynes, R. K., Wilson, N. L., et al. (2011). In vitro study of the anti-cancer effects of artemisone alone or in combination with other chemotherapeutic agents. Cancer Chemother. Pharmacol. 67, 569-577. doi: 10.1007/s00280-010-1355-4

Greenshields, A. L., Shepherd, T. G., and Hoskin, D. W. (2017). Contribution of reactive oxygen species to ovarian cancer cell growth arrest and killing by the anti-malarial drug artesunate. Mol. Carcinog 56, 75-93. doi: 10.1002/mc. 22474

Gu, Y., Wang, X., Wang, X., Yuan, M., Wu, G., Hu, J., et al. (2012). Artemisinin attenuates post-infarct myocardial remodeling by down-regulating the NF-кB pathway. Tohoku J. Exp. Med. 227, 161-170. doi: 10.1620/tjem.227.161

Guastalegname, M., and Vallone, A. (2020). Could chloroquine /hydroxychloroquine be harmful in coronavirus disease 2019 (COVID-19) treatment? Clin. Infect. Dis. 71, 888-889. doi: 10.1093/cid/ciaa321

Hamacher-Brady, A., Stein, H. A., Turschner, S., Toegel, I., Mora, R., Jennewein, N., et al. (2011). Artesunate activates mitochondrial apoptosis in breast cancer cells via iron-catalyzed lysosomal reactive oxygen species production. J. Biol. Chem. 286, 6587-6601. doi: 10.1074/jbc.M110.210047

Han, J., Wang, H., Kanagarajan, S., Hao, M., Lundgren, A., and Brodelius, P. E. (2016). Promoting artemisinin biosynthesis in Artemisia annua plants by substrate channeling. Mol. Plant 9, 946-948. doi: 10.1016/j.molp.2016.03.004

Hao, D. L., Xie, R., De, G. J., Yi, H., Zang, C., Yang, M. Y., et al. (2020). PHresponsive artesunate polymer prodrugs with enhanced ablation effect on rodent xenograft colon cancer. Int. J. Nanomedicine 15, 1771-1786. doi: 10. 2147/IJN.S242032

Hassanipour, S., Arab-Zozani, M., Amani, B., Heidarzad, F., Fathalipour, M., and Martinez-de-Hoyo, R. (2021). The efficacy and safety of favipiravir in treatment of COVID-19: a systematic review and meta-analysis of clinical trials. Sci. Rep. 11, 1-11. doi: 10.1038/s41598-021-90551-6

Heymann, D. L., and Shindo, N. (2020). COVID-19: what is next for public health? Lancet 395, 542-545. doi: 10.1016/S0140-6736(20)30374-3

Hu, W., Chen, S. S., Zhang, J. L., Lou, X. E., and Zhou, H. J. (2014). Dihydroartemisinin induces autophagy by suppressing NF- $\mathrm{B}$ activation. Cancer Lett. 343, 239-248. doi: 10.1016/j.canlet.2013.09.035

Hu, Y., Liu, M., Qin, H., Lin, H., An, X., Shi, Z., et al. (2021). Artemether, artesunate, arteannuin B, echinatin, licochalcone B and andrographolide effectively inhibit SARS-CoV-2 and related viruses in vitro. Front. Cell Infect. Microbiol. 11:1-8. doi: 10.3389/fcimb.2021.680127

Huang, J., Tao, G., Liu, J., Cai, J., Huang, Z., and Chen, J. X. (2020). Current prevention of COVID-19: natural products and herbal medicine. Front. Pharmacol. 11:1-18. doi: 10.3389/fphar.2020.588508

Hwang, Y. P., Yun, H. J., Kim, H. G., Han, E. H., Lee, G. W., and Jeong, H. G. (2010). Suppression of PMA-induced tumor cell invasion by dihydroartemisinin via 
inhibition of PKC $\alpha /$ Raf/MAPKs and NF-кB/AP-1-dependent mechanisms. Biochem. Pharmacol. 79, 1714-1726. doi: 10.1016/j.bcp.2010.02.003

Iannicelli, J., Guariniello, J., Tossi, V. E., Regalado, J. J., Di Ciaccio, L., van Baren, C. M., et al. (2020). The "polyploid effect" in the breeding of aromatic and medicinal species. Sci. Hortic. 260:108854. doi: 10.1016/j.scienta.2019.108854

Ikram, N. K., Beyraghdar Kashkooli, A., Peramuna, A., van der Krol, A. R., Bouwmeester, H., and Simonsen, H. T. (2019). Insights into heterologous biosynthesis of arteannuin B and artemisinin in physcomitrella patens. Molecules 24:822. doi: 10.3390/molecules24213822

Ikram, N. K. B. K., Beyraghdar Kashkooli, A., Peramuna, A. V., van der Krol, A. R., Bouwmeester, H., and Simonsen, H. T. (2017). Stable production of the antimalarial drug artemisinin in the moss physcomitrella patens. Front. Bioeng. Biotechnol. 5:1-8. doi: 10.3389/fbioe.2017.00047

Ikram, N. K. B. K., and Simonsen, H. T. (2017). A review of biotechnological artemisinin production in plants. Front. Plant Sci. 8:1-10. doi: 10.3389/fpls. 2017.01966

Ilamathi, M., Prabu, P. C., Ayyappa, K. A., and Sivaramakrishnan, V. (2016). Artesunate obliterates experimental hepatocellular carcinoma in rats through suppression of IL-6-JAK-STAT signalling. Biomed. Pharmacother. 82, 72-79. doi: 10.1016/j.biopha.2016.04.061

Immethun, C. M., Hoynes-O'Connor, A. G., Balassy, A., and Moon, T. S. (2013). Microbial production of isoprenoids enabled by synthetic biology. Front. Microbiol. 4:1-8. doi: 10.3389/fmicb.2013.00075

Ishikawa, C., Senba, M., and Mori, N. (2020). Evaluation of artesunate for the treatment of adult T-cell leukemia/lymphoma. Eur. J. Pharmacol. 872:172953. doi: 10.1016/j.ejphar.2020.172953

Jamalzadeh, L., Ghafoori, H., Aghamaali, M., and Sariri, R. (2017). Induction of apoptosis in human breast cancer MCF-7 cells by a semi- synthetic derivative of artemisinin: a caspase-related mechanism. Iran. J. Biotechnol. 15, 157-165. doi: $10.15171 /$ ijb.1567

Javed, H., Meeran, M. F. N., Jha, N. K., and Ojha, S. (2021). Carvacrol, a plant metabolite targeting viral protease (Mpro) and ACE2 in host cells can be a possible candidate for COVID-19. Front. Plant Sci. 11:1-10. doi: 10.3389/fpls. 2020.601335

Jelodar, N. B., Bhatt, A., Mohamed, K., and Keng, C. L. (2014). New cultivation approaches of Artemisia annua L. for a sustainable production of the antimalarial drug artemisinin. J. Med. Plants Res. 8, 441-447. doi: 10.5897/ JMPR11.1053

Jha, P., Ram, M., Khan, M. A., Kiran, U., and Abdin, M. Z. (2011). Impact of organic manure and chemical fertilizers on artemisinin content and yield in Artemisia annua L. Int. Crop. Prod. 33, 296-301. doi: 10.1016/j.indcrop.2010. 12.011

Jiang, F., Zhou, J. Y., Zhang, D., Liu, M. H., and Chen, Y. G. (2018). Artesunate induces apoptosis and autophagy in HCT116 colon cancer cells, and autophagy inhibition enhances the artesunate-induced apoptosis. Int. J. Mol. Med. 42, 1295-1304. doi: 10.3892/ijmm.2018.3712

Jiang, J., Geng, G., Yu, X., Liu, H., Gao, J., An, H., et al. (2016). Repurposing the anti-malarial drug dihydroartemisinin suppresses metastasis of non-smallcell lung cancer via inhibiting NF-KB/GLUT1 axis. Oncotarget 7, 87271-87283. doi: 10.18632/oncotarget.13536

Jiang, W., Fu, X., Pan, Q., Tang, Y., Shen, Q., Lv, Z., et al. (2016). Overexpression of AaWRKY1 leads to an enhanced content of artemisinin in Artemisia annua. Biomed Res. Int. 2016:971. doi: 10.1155/2016/7314971

Jiang, W., Huang, Y., Wang, J. P., Yu, X. Y., and Zhang, L. Y. (2013). The synergistic anticancer effect of artesunate combined with allicin in osteosarcoma cell line in vitro and in vivo. Asian Pacific J. Cancer Prev. 14, 4615-4619. doi: 10.7314/ APJCP.2013.14.8.4615

Jiang, Z., Chai, J., Chuang, H. H. F., Li, S., Wang, T., Cheng, Y., et al. (2012). Artesunate induces G0/G1 cell cycle arrest and iron-mediated mitochondrial apoptosis in A431 human epidermoid carcinoma cells. Anticancer. Drugs 23, 606-613. doi: 10.1097/CAD.0b013e328350e8ac

Jiao, Y., Ge, C. M., Meng, Q. H., Cao, J. P., Tong, J., and Fan, S. J. (2007). Dihydroartemisinin is an inhibitor of ovarian cancer cell growth. Acta Pharmacol. Sin. 28, 1045-1056. doi: 10.1111/j.1745-7254.2007.00612.x

Judd, R., Bagley, M. C., Li, M., Zhu, Y., Lei, C., Yuzuak, S., et al. (2019). Artemisinin biosynthesis in non-glandular trichome cells of Artemisia annua. Mol. Plant 12, 704-714. doi: 10.1016/j.molp.2019.02.011
Kapepula, P. M., Kabengele, J. K., Kingombe, M., van Bambeke, F., Tulkens, P. M., Kishabongo, A. S., et al. (2020). Artemisia spp. derivatives for COVID-19 treatment: anecdotal use, political hype, treatment potential, challenges, and road map to randomized clinical trials. Am. J. Trop. Med. Hyg. 103, 960-964. doi: 10.4269/ajtmh.20-0820

Kiani, B. H., Suberu, J., and Mirza, B. (2016). Cellular engineering of Artemisia annua and Artemisia dubia with the rol $\mathrm{ABC}$ genes for enhanced production of potent anti-malarial drug artemisinin. Malar. J. 15, 1-17. doi: 10.1186/s12936016-1312-8

Klayman, D. L. (1985). Qinghaosu (artemisinin): an antimalarial drug from china. Published by: American. Science 228, 1049-1055.

Koi, H., Takahashi, N., Fuchi, Y., Umeno, T., Muramatsu, Y., Seimiya, H., et al. (2020). A fully synthetic 6-aza-artemisinin bearing an amphiphilic chain generates aggregates and exhibits anti-cancer activities. Org. Biomol. Chem. 18, 5339-5343. doi: 10.1039/d0ob00919a

Koshak, D. A. E., and Koshak, P. E. A. (2020). Nigella sativa L as a potential phytotherapy for coronavirus disease 2019: a mini review of in silico studies. Curr. Ther. Res. 93:100602. doi: 10.1016/j.curtheres.2020.100602

Krishna, S., Ganapathi, S., Ster, I. C., Saeed, M. E. M., Cowan, M., Finlayson, C., et al. (2015). A randomised, double blind, placebo-controlled pilot study of oral artesunate therapy for colorectal cancer. EBioMedicine 2, 82-90. doi: 10.1016/j.ebiom.2014.11.010

Kshirsagar, S. G., and Rao, R. V. (2021). Antiviral and immunomodulation effects of Artemisia. Medicine 57, 1-12. doi: 10.3390/medicina57030217

Kumar, V. L., Verma, S., and Das, P. (2019). Artesunate suppresses inflammation and oxidative stress in a rat model of colorectal cancer. Drug Dev. Res. 80, 1089-1097. doi: 10.1002/ddr.21590

Lai, C. C., Shih, T. P., Ko, W. C., Tang, H. J., and Hsueh, P. R. (2020). Severe acute respiratory syndrome coronavirus 2 (SARS-CoV-2) and coronavirus disease2019 (COVID-19): the epidemic and the challenges. Int. J. Antimicrob. Agents 55:105924. doi: 10.1016/j.ijantimicag.2020.105924

Lai, H., Nakase, I., Lacoste, E., Singh, N. P., and Sasaki, T. (2009). Artemisinintransferrin conjugate retards growth of breast tumors in the rat. Anticancer Res. 29, 3807-3810.

Lai, H., Sasaki, T., Singh, N. P., and Messay, A. (2005). Effects of artemisinin-tagged holotransferrin on cancer cells. Life Sci. 76, 1267-1279. doi: 10.1016/j.lfs.2004. 08.020

Lai, H., and Singh, N. P. (2006). Oral artemisinin prevents and delays the development of 7,12-dimethylbenz[a]anthracene (DMBA)-induced breast cancer in the rat. Cancer Lett. 231, 43-48. doi: 10.1016/j.canlet.2005.01.019

Lai, L., Chen, Y., Tian, X., Li, X., Zhang, X., Lei, J., et al. (2015). Artesunate alleviates hepatic fibrosis induced by multiple pathogenic factors and inflammation through the inhibition of LPS/TLR4/NF-kB signaling pathway in rats. Eur. J. Pharmacol. 765, 234-241. doi: 10.1016/j.ejphar.2015.08.040

Langroudi, L., Hassan, Z. M., Ebtekar, M., Mahdavi, M., Pakravan, N., and Noori, S. (2010). A comparison of low-dose cyclophosphamide treatment with artemisinin treatment in reducing the number of regulatory $\mathrm{T}$ cells in murine breast cancer model. Int. Immunopharmacol. 10, 1055-1061. doi: 10.1016/j. intimp.2010.06.005

Larson, S. A., Dolivo, D. M., and Dominko, T. (2019). Artesunate inhibits myofibroblast formation via induction of apoptosis and antagonism of profibrotic gene expression in human dermal fibroblasts. Cell Biol. Int. 43, 13171322. doi: 10.1002/cbin.11220

Lei, C., Ma, D., Pu, G., Qiu, X., Du, Z., Wang, H., et al. (2011). Foliar application of chitosan activates artemisinin biosynthesis in artemisia. Int. Crop. Prod. 33, 176-182. doi: 10.1016/j.indcrop.2010.10.001

Leow, E. S., Jelodar, N. B., and Chan, L. K. (2020). Ethyl methane sulfonate (Ems) enhanced the formation of leaf glandular trichomes and the production of artemisinin in Artemisia annua L. Asia Pacific J. Sci. Technol. 25, 1-9.

Li, B., Bu, S., Sun, J., Guo, Y., and Lai, D. (2018). Artemisinin derivatives inhibit epithelial ovarian cancer cells via autophagy-mediated cell cycle arrest. Acta Biochim. Biophys. Sin. 50, 1227-1235. doi: 10.1093/abbs/ gmy125

Li, G., Yuan, M., Li, H., Deng, C., Wang, Q., Tang, Y., et al. (2020). Safety and efficacy of artemisinin-piperaquine for treatment of COVID-19: an open-label, non-randomised and controlled trial. Int. J. Antimicrob. Agents 57:106216. doi: 10.1016/j.ijantimicag.2020.106216 
Li, H., Xu, K., Pian, G., and Sun, S. (2019). Artesunate and sorafenib: combinatorial inhibition of liver cancer cell growth. Oncol. Lett. 18, 4735-4743. doi: 10.3892/ ol.2019.10810

Li, J., Feng, W., Lu, H., Wei, Y., Ma, S., Wei, L., et al. (2019). Artemisinin inhibits breast cancer-induced osteolysis by inhibiting osteoclast formation and breast cancer cell proliferation. J. Cell. Physiol. 234, 12663-12675. doi: 10.1002/jcp. 27875

Li, L. N., Zhang, H. D., Yuan, S. J., Tian, Z. Y., Wang, L., and Sun, Z. X. (2007). Artesunate attenuates the growth of human colorectal carcinoma and inhibits hyperactive Wnt/ $\beta$-catenin pathway. Int. J. Cancer 121, 1360-1365. doi: 10. $1002 / \mathrm{ijc} .22804$

Li, L. N., Zhang, H. D., Yuan, S. J., Yang, D. X., Wang, L., and Sun, Z. X. (2008). Differential sensitivity of colorectal cancer cell lines to artesunate is associated with expression of beta-catenin and E-cadherin. Eur. J. Pharmacol. 588, 1-8. doi: 10.1016/j.ejphar.2008.03.041

Li, W., Ma, G., Deng, Y., Wu, Q., Wang, Z., and Zhou, Q. (2021). Artesunate exhibits synergistic anti-cancer effects with cisplatin on lung cancer A549 cells by inhibiting MAPK pathway. Gene 766:145134. doi: 10.1016/j.gene.2020. 145134

Li, X., Ba, Q., Liu, Y., Yue, Q., Chen, P., Li, J., et al. (2017). Dihydroartemisinin selectively inhibits PDGFR $\alpha$-positive ovarian cancer growth and metastasis through inducing degradation of PDGFRá protein. Cell .Discov. 3, 1-13. doi: 10.1038 /celldisc. 2017.42

Li, X., Gu, S., Sun, D., Dai, H., Chen, H., and Zhang, Z. (2018). The selectivity of artemisinin-based drugs on human lung normal and cancer cells. Environ. Toxicol. Pharmacol. 57, 86-94. doi: 10.1016/j.etap.2017.12.004

Li, Y., Sui, H., Jiang, C., Li, S., Han, Y., Huang, P., et al. (2018). Dihydroartemisinin increases the sensitivity of photodynamic therapy via NF-кB/HIF-1 $\alpha /$ VEGF pathway in esophageal cancer cell in vitro and in vivo. Cell Physiol. Biochem. 48, 2035-2045. doi: 10.1159/000492541

Li, Y. J., Zhou, J. H., Du, X. X., Jia, D. X., Wu, C. L., Huang, P., et al. (2014). Dihydroartemisinin accentuates the anti-tumor effects of photodynamic therapy via inactivation of NF-кB in Eca109 and Ec9706 esophageal cancer cells. Cell Physiol. Biochem. 33, 1527-1536. doi: 10.1159/000358716

Liang, W., Liu, J., Wu, H., Qiao, X., Lu, X., Liu, Y., et al. (2019). Artemisinin induced reversal of EMT affects the molecular biological activity of ovarian cancer SKOV3 cell lines. Oncol. Lett. 18, 3407-3414. doi: 10.3892/ol.2019.10608

Liao, P., Hemmerlin, A., Bach, T. J., and Chye, M. (2016). The potential of the mevalonate pathway for enhanced isoprenoid production. Biotechnol. Adv. 34, 697-713. doi: 10.1016/j.biotechadv.2016.03.005

Lin, X., Zhou, Y., Zhang, J., Lu, X., Zhang, F., Shen, Q., et al. (2011). Enhancement of artemisinin content in tetraploid Artemisia annua plants by modulating the expression of genes in artemisinin biosynthetic pathway. Biotechnol. Appl. Biochem. 58, 50-57. doi: 10.1002/bab.13

Lindahl, A. L., Olsson, M. E., Mercke, P., Tollbom, Ö, Schelin, J., Brodelius, M., et al. (2006). Production of the artemisinin precursor amorpha-4,11-diene by engineered Saccharomyces cerevisiae. Biotechnol. Lett. 28, 571-580. doi: 10. 1007/s10529-006-0015-6

Liu, B., Wang, H., Du, Z., Li, G., and Ye, H. (2011). Metabolic engineering of artemisinin biosynthesis in Artemisia annua L. Plant Cell Rep. 30, 689-694. doi: 10.1007/s00299-010-0967-9

Liu, C., Xu, Y. W. X., Ouyang, F., Ye, H., and Li, G. (1999). Improvement of artemisinin accumulation in hairy root cultures of Artemisia annua L by fungal elicitor. Bioproc. Eng. 20, 161-164. doi: 10.1007/PL00009041

Liu, T., Zhang, J., Yang, Y., Ma, H., Li, Z., Zhang, J., et al. (2020). The role of interleukin-6 in monitoring severe case of coronavirus disease 2019. EMBO Mol. Med. 12:e12421. doi: 10.15252/emmm.202012421

Liu, T., Zhang, L., Joo, D., and Sun, S. C. (2017). NF- $\kappa$ B signaling in inflammation. Signal Transduct. Target. Ther. 2:23. doi: 10.1038/sigtrans.2017.23

Liu, Y., Gao, S., Zhu, J., Zheng, Y., Zhang, H., and Sun, H. (2018). Dihydroartemisinin induces apoptosis and inhibits proliferation, migration, and invasion in epithelial ovarian cancer via inhibition of the hedgehog signaling pathway. Cancer Med. 7, 5704-5715. doi: 10.1002/cam4.1827

Lu, J. J., Chen, S. M., Zhang, X. W., Ding, J., and Meng, L. H. (2011). The anti-cancer activity of dihydroartemisinin is associated with induction of irondependent endoplasmic reticulum stress in colorectal carcinoma HCT116 cells. Invest. New Drugs 29, 1276-1283. doi: 10.1007/s10637-010-9481-8
Lu, R., Zhao, X., Li, J., Niu, P., Yang, B., Wu, H., et al. (2020). Genomic characterisation and epidemiology of 2019 novel coronavirus: implications for virus origins and receptor binding. Lancet 395, 565-574. doi: 10.1016/S01406736(20)30251-8

Luo, J., Zhu, W., Tang, Y., Cao, H., Zhou, Y., Ji, R., et al. (2014). Artemisinin derivative artesunate induces radiosensitivity in cervical cancer cells in vitro and in vivo. Radiat. Oncol. 9, 1-12. doi: 10.1186/1748-717X-9-84

Lv, Z., Zhang, L., and Tang, K. (2017). New insights into artemisinin regulation. Plant Signal. Behav. 12:1366398. doi: 10.1080/15592324.2017.1366398

Lyu, M., Fan, G., Xiao, G., Wang, T., Xu, D., Gao, J., et al. (2021). Traditional chinese medicine in COVID-19. Acta Pharm. Sin. B 11, 3337-3363. doi: 10. 1016/j.apsb.2021.09.008

Ma, D., Li, G., Alejos-Gonzalez, F., Zhu, Y., Xue, Z., Wang, A., et al. (2017). Overexpression of a type-I isopentenyl pyrophosphate isomerase of Artemisia annua in the cytosol leads to high arteannuin B production and artemisinin increase. Plant J. 91, 466-479. doi: 10.1111/tpj.13583

Ma, D., Pu, G., Lei, C., Ma, L., Wang, H., Guo, Y., et al. (2009). Isolation and characterization of AaWRKY1, an Artemisia annua transcription factor that regulates the amorpha-4,11-diene synthase gene, a key gene of artemisinin biosynthesis. Plant Cell Physiol. 50, 2146-2161. doi: 10.1093/pcp/pcp149

Ma, D. M., Wang, Z., Wang, L., Alejos-Gonzales, F., Sun, M. A., and Xie, D. Y. (2015). A genome-wide scenario of terpene pathways in self-pollinated Artemisia annua. Mol. Plant 8, 1580-1598. doi: 10.1016/j.molp.2015.07.004

Ma, H., Yao, Q., Zhang, A. M., Lin, S., Wang, X. X., Wu, L., et al. (2011). The effects of artesunate on the expression of EGFR and ABCG2 in A549 human lung cancer cells and a xenograft model. Molecules 16, 10556-10569. doi: 10. 3390/molecules161210556

Ma, Y.-N., Xu, D.-B., Li, L., Zhang, F., Fu, X.-Q., Shen, Q., et al. (2018). Jasmonate promotes artemisinin biosynthesis by activating the TCP14-ORA complex in Artemisia annua. Sci. Adv. 4:eaas9357. doi: 10.1126/sciadv.aas9357

Malhotra, K., Subramaniyan, M., Rawat, K., Kalamuddin, M., Qureshi, M. I., Malhotra, P., et al. (2016). Compartmentalized metabolic engineering for artemisinin biosynthesis and effective malaria treatment by oral delivery of plant cells. Mol. Plant 9, 1464-1477. doi: 10.1016/j.molp.2016.09.013

Mandal, S., Upadhyay, S., Wajid, S., Ram, M., Jain, D. C., Singh, V. P., et al. (2014). Arbuscular mycorrhiza increase artemisinin accumulation in Artemisia annua by higher expression of key biosynthesis genes via enhanced jasmonic acid levels. Mycorrhiza 25:25366131. doi: 10.1007/s00572-014-0614-3

Mani, J. S., Johnson, J. B., Steel, J. C., Broszczak, D. A., Neilsen, P. M., Walsh, K. B., et al. (2020). Natural product-derived phytochemicals as potential agents against coronaviruses: a review. Virus Res. 284:197989. doi: 10.1016/j.virusres. 2020.197989

Mao, H., Gu, H., Qu, X., Sun, J., Song, B., Gao, W., et al. (2013). Involvement of the mitochondrial pathway and $\mathrm{Bim} / \mathrm{Bcl}-2$ balance in dihydroartemisinin-induced apoptosis in human breast cancer in vitro. Int. J. Mol. Med. 31, 213-218. doi: 10.3892/ijmm.2012.1176

Martin, V. J. J., Pitera, D. J., Withers, S. T., Newman, J. D., and Keasling, J. D. (2003). Engineering a mevalonate pathway in Escherichia coli for production of terpenoids. Nat. Biotechnol. 21, 796-802. doi: 10.1038/nbt833

Mbengue, A., Bhattacharjee, S., Pandharkar, T., Liu, H., Estiu, G., Stahelin, R. V., et al. (2015). A molecular mechanism of artemisinin resistance in Plasmodium falciparum malaria. Nature 520, 683-687. doi: 10.1038/nature14412

McDowell, A., Hill, K. S., McCorkle, J. R., Gorski, J., Zhang, Y., Salahudeen, A. A., et al. (2021). Preclinical evaluation of artesunate as an antineoplastic agent in ovarian cancer treatment. Diagnostics 11:395. doi: 10.3390/ diagnostics11030395

Mehta, P., McAuley, D. F., Brown, M., Sanchez, E., Tattersall, R. S., and Manson, J. J. (2020). COVID-19: consider cytokine storm syndromes and immunosuppression. Lancet 395, 1033-1034. doi: 10.1016/S0140-6736(20) 30628-0

Mercke, P., Bengtsson, M., Bouwmeester, H. J., Posthumus, M. A., and Brodelius, P. E. (2000). Molecular cloning, expression, and characterization of amorpha4,11-diene synthase, a key enzyme of artemisinin biosynthesis in Artemisia annua L. Arch. Biochem. Biophys. 381, 173-180. doi: 10.1006/abbi.2000.1962

Mert, A., K1r1c1, S., and Ayanoğlu, F. (2002). The effects of different plant densities on yield, yield components and quality of Artemisia annua L. ecotypes. J. Herbs. Spices Med. Plants 9, 413-418. doi: 10.1300/J044v09n04_20 
Michaelis, M., Kleinschmidt, M. C., Barth, S., Rothweiler, F., Geiler, J., Breitling, R., et al. (2010). Anti-cancer effects of artesunate in a panel of chemoresistant neuroblastoma cell lines. Biochem. Pharmacol. 79, 130-136. doi: 10.1016/j.bcp. 2009.08.013

Mok, S., Ashley, E. A., Ferreira, P. E., Zhu, L., Lin, Z., Yeo, T., et al. (2015). Population transcriptomics of human malaria parasites reveals the mechanism of artemisinin resistance. Science 347, 431-435. doi: 10.1126/science.1260403

Mondal, A., and Chatterji, U. (2015). Artemisinin represses telomerase subunits and induces apoptosis in HPV-39 Infected human cervical cancer cells. J. Cell. Biochem. 116, 1968-1981. doi: 10.1002/jcb.25152

Muhammad, A., Feng, X., Rasool, A., Sun, W., and Li, C. (2020). Production of plant natural products through engineered Yarrowia lipolytica. Biotechnol. Adv. 43:107555. doi: 10.1016/j.biotechadv.2020.107555

Nafis, T., Akmal, M., Ram, M., Alam, P., Ahlawat, S., Mohd, A., et al. (2011). Enhancement of artemisinin content by constitutive expression of the HMGCoA reductase gene in high-yielding strain of Artemisia annua L. Plant Biotechnol. Rep. 5, 53-60. doi: 10.1007/s11816-010-0156-x

Nair, M. S., Huang, Y., Fidock, D. A., Towler, M. J., and Weathers, P. J. (2022). Artemisia annua L. hot-water extracts show potent activity in vitro against Covid-19 variants including delta. J. Ethnopharmacol. 284:114797. doi: 10.1016/ j.jep.2021.114797

Nakase, I., Gallis, B., Takatani-Nakase, T., Oh, S., Lacoste, E., Singh, N. P., et al. (2009). Transferrin receptor-dependent cytotoxicity of artemisinin-transferrin conjugates on prostate cancer cells and induction of apoptosis. Cancer Lett. 274, 290-298. doi: 10.1016/j.canlet.2008.09.023

Nazrul Islam, M., Hossain, K. S., Sarker, P. P., Ferdous, J., Hannan, M. A., Rahman, M. M., et al. (2021). Revisiting pharmacological potentials of Nigella sativa seed: a promising option for COVID-19 prevention and cure. Phyther. Res. 35 , 1329-1344. doi: 10.1002/ptr.6895

Newman, J. D., Marshall, J., Chang, M., Nowroozi, F., Paradise, E., Pitera, D., et al. (2006). High-level production of amorpha-4,11-diene in a two-phase partitioning bioreactor of metabolically engineered Escherichia coli. Biotechnol. Bioeng. 95, 684-691. doi: 10.1002/bit.21017

Nie, C., Trimpert, J., Moon, S., Haag, R., Gilmore, K., Kaufer, B. B., et al. (2021). In vitro efficacy of artemisia extracts against SARS-CoV-2. Virol. J. 18, 1-7. doi: 10.1186/s12985-021-01651-8

Nunes, J. J., Pandey, S. K., Yadav, A., Goel, S., and Ateeq, B. (2017). Targeting NFkappa B signaling by artesunate restores sensitivity of castrate-resistant prostate cancer cells to antiandrogens. Neoplasia 19, 333-345. doi: 10.1016/j.neo.2017. 02.002

Ohgami, Y., Elstad, C. A., Chung, E., Shirachi, D. Y., Quock, R. M., and Lai, H. C. (2010). Effect of hyperbaric oxygen on the anticancer effect of artemisinin on molt-4 human leukemia cells. Anticancer Res. 30, 4467-4470.

O'Neill, P. M., Barton, V. E., and Ward, S. A. (2010). The molecular mechanism of action of artemisinin-the debate continues. Molecules 15, 1705-1721. doi: 10.3390/molecules 15031705

Ooko, E., Saeed, M. E. M., Kadioglu, O., Sarvi, S., Colak, M., Elmasaoudi, K., et al. (2015). Artemisinin derivatives induce iron-dependent cell death (ferroptosis) in tumor cells. Phytomedicine 22, 1045-1054. doi: 10.1016/j.phymed.2015.08. 002

Orege, J. I., Adeyemi, S. B., Tiamiyu, B. B., Akinyemi, T. O., Ibrahim, Y. A., and Orege, O. B. (2021). Artemisia and artemisia-based products for COVID-19 management: current state and future perspective. Adv. Tradit. Med. 5, 1-12. doi: 10.1007/s13596-021-00576-5

Osaki, T., Uto, Y., Ishizuka, M., Tanaka, T., Yamanaka, N., Kurahashi, T., et al. (2017). Artesunate enhances the cytotoxicity of 5-aminolevulinic acid-based sonodynamic therapy against mouse mammary tumor cells in vitro. Molecules 22:533. doi: $10.3390 /$ molecules22040533

Paddon, C. J., and Keasling, J. D. (2014). Semi-synthetic artemisinin: a model for the use of synthetic biology in pharmaceutical development. Nat. Rev. Microbiol. 12, 355-367. doi: 10.1038/nrmicro3240

Paddon, C. J., Westfall, P. J., Pitera, D. J., Benjamin, K., Fisher, K., McPhee, D., et al. (2013). High-level semi-synthetic production of the potent antimalarial artemisinin. Nature 496, 528-532. doi: 10.1038/nature12051

Pahl, H. L. (1999). Activators and target genes of Rel/NF- $\kappa B$ transcription factors. Oncogene 18, 6853-6866. doi: 10.1038/sj.onc.1203239

Pandey, N., and Pandey-Rai, S. (2014). Short term UV-B radiation-mediated transcriptional responses and altered secondary metabolism of in vitro propagated plantlets of Artemisia annua L. Plant Cell, Tissue Organ Cult. 116, 371-385. doi: 10.1007/s11240-013-0413-0

Paradise, E. M., Kirby, J., Chan, R., and Keasling, J. D. (2008). Redirection of flux through the FPP branch-point in Saccharomyces cerevisiae by down-regulating squalene synthase. Biotechnol. Bioeng. 100, 371-378. doi: 10.1002/bit.2 1766

Parshikov, I. A., Netrusov, A. I., and Sutherland, J. B. (2012). Microbial transformation of antimalarial terpenoids. Biotechnol. Adv. 30, 1516-1523. doi: 10.1016/j.biotechadv.2012.03.010

Pirali, M., Taheri, M., Zarei, S., Majidi, M., and Ghafouri, H. (2020). Artesunate, as a HSP70 ATPase activity inhibitor, induces apoptosis in breast cancer cells. Int. J. Biol. Macromol. 164, 3369-3375. doi: 10.1016/j.ijbiomac.2020.08.198

Pitera, D. J., Paddon, C. J., Newman, J. D., and Keasling, J. D. (2007). Balancing a heterologous mevalonate pathway for improved isoprenoid production in Escherichia coli. Metab. Eng. 9, 193-207. doi: 10.1016/j.ymben.2006.11.002

Qi, H., Li, B., Zhang, W., Liu, D., and Yuan, Y. (2015). Modularization of genetic elements promotes synthetic metabolic engineering. Biotechnol. Adv. 33, 1412-1419. doi: 10.1016/j.biotechadv.2015.04.002

Rasheed, S. A. K., Efferth, T., Asangani, I. A., and Allgayer, H. (2010). First evidence that the antimalarial drug artesunate inhibits invasion and in vivo metastasis in lung cancer by targeting essential extracellular proteases. Int. J. Cancer 127, 1475-1485. doi: 10.1002/ijc.25315

Raymond, M., Miriam, K., Oliver, K., Edwin, M., and Stephen, K. (2015). Enhancement of artemisinin in Artemisia annua L. through induced mutation. OALib 02, 1-11. doi: 10.4236/oalib.1102189

Raza, A., Ghoshal, A., Chockalingam, S., and Ghosh, S. S. (2017). Connexin-43 enhances tumor suppressing activity of artesunate via gap junction-dependent as well as independent pathways in human breast cancer cells. Sci. Rep. 7, 1-13. doi: 10.1038/s41598-017-08058-y

Reed, J., Stephenson, M. J., Miettinen, K., Brouwer, B., Leveau, A., Brett, P., et al. (2017). A translational synthetic biology platform for rapid access to gramscale quantities of novel drug-like molecules. Metab. Eng. 42, 185-193. doi: 10.1016/j.ymben.2017.06.012

Ribaudo, G., Coghi, P., Yang, L. J., Ng, J. P. L., Mastinu, A., Memo, M., et al. (2021). Computational and experimental insights on the interaction of artemisinin, dihydroartemisinin and chloroquine with SARS-CoV-2 spike protein receptorbinding domain (RBD). Nat. Prod. Res. 33, 1-6. doi: 10.1080/14786419.2021. 1925894

Riganti, C., Doublier, S., Viarisio, D., Miraglia, E., Pescarmona, G., Ghigo, D., et al. (2009). Artemisinin induces doxorubicin resistance in human colon cancer cells via calcium-dependent activation of HIF- $1 \alpha$ and P-glycoprotein overexpression. Br. J. Pharmacol. 156, 1054-1066. doi: 10.1111/j.1476-5381. 2009.00117.x

Ro, D. K., Ouellet, M., Paradise, E. M., Burd, H., Eng, D., Paddon, C. J., et al. (2008). Induction of multiple pleiotropic drug resistance genes in yeast engineered to produce an increased level of anti-malarial drug precursor, artemisinic acid. BMC Biotechnol. 8:1-14. doi: 10.1186/1472-6750-8-83

Ro, D. K., Paradise, E. M., Quellet, M., Fisher, K. J., Newman, K. L., Ndungu, J. M., et al. (2006). Production of the antimalarial drug precursor artemisinic acid in engineered yeast. Nature 440, 940-943. doi: 10.1038/nature 04640

Roh, J. L., Kim, E. H., Jang, H., and Shin, D. (2017). Nrf2 inhibition reverses the resistance of cisplatin-resistant head and neck cancer cells to artesunateinduced ferroptosis. Redox Biol. 11, 254-262. doi: 10.1016/j.redox.2016. 12.010

Rolta, R., Salaria, D., Kumar, V., Sourirajan, A., and Dev, K. (2020). Phytocompounds of Rheum emodi, Thymus serpyllum and Artemisia annua inhibit COVID-19 binding to ACE2 receptor: in silico approach. Curr. Pharmacol. Rep. doi: 10.21203/rs.3.rs-30938/v1 [Epub ahead of print],

Sa, G., Mi, M., He-chun, Y., Ben-ye, L., Guo-feng, L., and Kang, C. (2001). Effects of ipt gene expression on the physiological and chemical characteristics of Artemisia annua L. Plant Sci. 160, 691-698. doi: 10.1016/S0168-9452(00) 00453-2

Sarma, B., Willmes, C., Angerer, L., Adam, C., Becker, J. C., Kervarrec, T., et al. (2020). Artesunate affects $\mathrm{T}$ antigen expression and survival of virus-positive merkel cell carcinoma. Cancers 12, 1-15. doi: 10.3390/cancers 12040919

Schramek, N., Wang, H., Römisch-Margl, W., Keil, B., Radykewicz, T., Winzenhörlein, B., et al. (2010). Artemisinin biosynthesis in growing plants of 
Artemisia annua. a 13CO2 study. Phytochemistry 71, 179-187. doi: 10.1016/j. phytochem.2009.10.015

Sehailia, M., and Chemat, S. (2020). Antimalarial-agent artemisinin and derivatives portray more potent binding to Lys353 and Lys31-binding hotspots of SARS-CoV-2 spike protein than hydroxychloroquine: potential repurposing of artenimol for COVID-19. J. Biomol. Struct. Dyn. 39, 6184-6194. doi: 10.1080/ 07391102.2020.1796809

Shandilya, A., Chacko, S., Jayaram, B., and Ghosh, I. (2013). A plausible mechanism for the antimalarial activity of artemisinin: a computational approach. Sci. Rep. 3, 1-7. doi: 10.1038/srep02513

Shen, Q., Chen, Y. F., Wang, T., Wu, S. Y., Lu, X., Zhang, L., et al. (2012). Overexpression of the cytochrome P450 monooxygenase (cyp7lav1) and cytochrome $\mathrm{P} 450$ reductase (cpr) genes increased artemisinin content in Artemisia annua (asteraceae). Genet. Mol. Res. 11, 3298-3309. doi: 10.4238/ 2012.September.12.13

Shen, Q., Yan, T., Fu, X., and Tang, K. (2016). Transcriptional regulation of artemisinin biosynthesis in Artemisia annua L. Sci. Bull. 61, 18-25. doi: 10.1007/ s11434-015-0983-9

Shi, R., Cui, H., Bi, Y., Huang, X., Song, B., Cheng, C., et al. (2015). Artesunate altered cellular mechanical properties leading to deregulation of cell proliferation and migration in esophageal squamous cell carcinoma. Oncol. Lett. 9, 2249-2255. doi: 10.3892/ol.2015.2982

Singh, N. P., and Lai, H. C. (2004). Artemisinin induces apoptosis in human cancer cells. Anticancer Res. 24, 2277-2280.

Singh, N. P., and Verma, K. B. (2002). Case report of a laryngeal squamous cell carcinoma treated with artesunate. Arch. Oncol. 10, 279-280. doi: 10.2298/ AOO0204279S

Singhal, T. (2020). A review of coronavirus disease-2019 (COVID-19). Indian J. Pediatr. 87, 281-286. doi: 10.1007/s12098-020-03263-6

Song, J., Zhang, L., Xu, Y., Yang, D., Yang, S., Zhang, W., et al. (2021). The comprehensive study on the therapeutic effects of baicalein for the treatment of COVID-19 in vivo and in vitro. Biochem. Pharmacol. 183:114302. doi: 10 . 1016/j.bcp.2020.114302

Srivastava, N. K., and Sharma, S. (1990). Influence of micronutrient imbalance on growth and artemisinin content in Artemisia annua. Indian J. Pharm. Sci. 52, 225-227.

Su, T., Li, F., Guan, J., Liu, L., Huang, P., Wang, Y., et al. (2019). Artemisinin and its derivatives prevent helicobacter pylori-induced gastric carcinogenesis via inhibition of NF- $\kappa \mathrm{B}$ signaling. Phytomedicine 63:152968. doi: 10.1016/j. phymed.2019.152968

Subedi, A., Futamura, Y., Nishi, M., Ryo, A., Watanabe, N., and Osada, H. (2016). High-throughput screening identifies artesunate as selective inhibitor of cancer stemness: involvement of mitochondrial metabolism. Biochem. Biophys. Res. Commun. 477, 737-742. doi: 10.1016/j.bbrc.2016.06.128

Sundar, S. N., Marconett, C. N., Doan, V. B., Willoughby, J. A., and Firestone, G. L. (2008). Artemisinin selectively decreases functional levels of estrogen receptoralpha and ablates estrogen-induced proliferation in human breast cancer cells. Carcinogenesis 29, 2252-2258. doi: 10.1093/carcin/bgn214

Tanaka, T., Narazaki, M., and Kishimoto, T. (2014). IL-6 in inflammation, immunity, and disease. Cold Spring Harb. Perspect. Biol. 6:a016295.

Tang, K., Shen, Q., Yan, T., and Fu, X. (2014). Transgenic approach to increase artemisinin content in Artemisia annua L. Plant Cell Rep. 33, 605-615. doi: 10.1007/s00299-014-1566-y

Teoh, K. H., Polichuk, D. R., Reed, D. W., Nowak, G., and Covello, P. S. (2006). Artemisia annua L. (asteraceae) trichome-specific cDNAs reveal CYP71AV1, a cytochrome $\mathrm{P} 450$ with a key role in the biosynthesis of the antimalarial sesquiterpene lactone artemisinin. FEBS Lett. 580, 1411-1416. doi: 10.1016/j. febslet.2006.01.065

Thanaketpaisarn, O., Waiwut, P., Sakurai, H., and Saiki, I. (2011). Artesunate enhances TRAIL-induced apoptosis in human cervical carcinoma cells through inhibition of the NF-кB and PI3K/Akt signaling pathways. Int. J. Oncol. 39, 279-285. doi: 10.3892/ijo.2011.1017

Tilley, L., Straimer, J., Gnädig, N. F., Ralph, S. A., and Fidock, D. A. (2016). Artemisinin action and resistance in Plasmodium falciparum. Trends Parasitol. 32, 682-696. doi: 10.1016/j.pt.2016.05.010

Tin, A. S., Sundar, S. N., Tran, K. Q., Park, A. H., Poindexter, K. M., and Firestone, G. L. (2012). Antiproliferative effects of artemisinin on human breast cancer cells requires the downregulated expression of the E2F1 transcription factor and loss of E2F1-target cell cycle genes. Anticancer. Drugs 23, 370-379. doi: 10.1097/CAD.0b013e32834f6ea8

Ting, H. M., Wang, B., Rydén, A. M., Woittiez, L., Van Herpen, T., Verstappen, F. W. A., et al. (2013). The metabolite chemotype of Nicotiana benthamiana transiently expressing artemisinin biosynthetic pathway genes is a function of CYP71AV1 type and relative gene dosage. New Phytol. 199, 352-366. doi: 10.1111/nph.12274

Tong, Y., Liu, Y., Zheng, H., Zheng, L., Liu, W., Wu, J., et al. (2016). Artemisinin and its derivatives can significantly inhibit lung tumorigenesis and tumor metastasis through Wnt/ $\beta$-catenin signaling. Oncotarget $7,31413-31428$. doi: 10.18632/oncotarget.8920

Tran, K. Q., Tin, A. S., and Firestone, G. L. (2014). Artemisinin triggers a G1 cell cycle arrest of human Ishikawa endometrial cancer cells and inhibits cyclindependent kinase-4 promoter activity and expression by disrupting nuclear factor-кB transcriptional signaling. Anticancer. Drugs 25, 270-281. doi: 10. 1097/CAD.0000000000000054

Tran, T. H., Nguyen, A. N., Kim, J. O., Yong, C. S., and Nguyen, C. N. (2016). Enhancing activity of artesunate against breast cancer cells via inducedapoptosis pathway by loading into lipid carriers. Artif. Cells Nanomed. Biotechnol. 44, 1979-1987. doi: 10.3109/21691401.2015.1129616

Tsuruta, H., Paddon, C. J., Eng, D., Lenihan, J. R., Horning, T., Anthony, L. C., et al. (2009). High-level production of amorpha-4, 11-diene, a precursor of the antimalarial agent artemisinin, in Escherichia coli. PLoS One 4:4489. doi: 10.1371/journal.pone.0004489

Tu, Y. (2011). The discovery of artemisinin (qinghaosu) and gifts from Chinese medicine. Nat. Med. 17, 1217-1220. doi: 10.1038/nm.2471

Uckun, F. M., Saund, S., Windlass, H., and Trieu, V. (2021). Repurposing antimalaria phytomedicine artemisinin as a COVID-19 drug. Front. Pharmacol. 12:1-5. doi: 10.3389/fphar.2021.649532

Ulhaq, Z. S., and Soraya, G. V. (2020). Interleukin-6 as a potential biomarker of COVID-19 progression. Med. Mal. Infect. 50, 382-383. doi: 10.1016/j.medmal. 2020.04.002

Uzun, T., and Toptas, O. (2020). Artesunate: could be an alternative drug to chloroquine in COVID-19 treatment? Chin. Med. 15:54. doi: 10.1186/s13020020-00336-8

van Herpen, T. W. J. M., Cankar, K., Nogueira, M., Bosch, D., Bouwmeester, H. J., and Beekwilder, J. (2010). Nicotiana benthamiana as a production platform for artemisinin precursors. PLoS One 5:14222. doi: 10.1371/journal.pone.0014222

Våtsveen, T. K., Myhre, M. R., Steen, C. B., Wälchli, S., Lingjærde, O. C., Bai, B., et al. (2018). Artesunate shows potent anti-tumor activity in B-cell lymphoma. J. Hematol. Oncol. 11, 1-12. doi: 10.1186/s13045-018-0561-0

Velazquez-Salinas, L., Verdugo-Rodriguez, A., Rodriguez, L. L., and Borca, M. V. (2019). The role of interleukin 6 during viral infections. Front. Microbiol. 10:6-11. doi: 10.3389/fmicb.2019.01057

Verma, I. M., Stevenson, J. K., Schwarz, E. M., and Van Antwerp, D. (1995). Rel/NF-kappa B/I kappa B family: intimate tales of association and dissociation. Genes Dev. 9, 2723-2735.

Verma, S., Das, P., and Kumar, V. L. (2017). Chemoprevention by artesunate in a preclinical model of colorectal cancer involves down regulation of $\beta$-catenin, suppression of angiogenesis, cellular proliferation and induction of apoptosis. Chem. Biol. Interact. 278, 84-91. doi: 10.1016/j.cbi.2017.10.011

Verma, S., Twilley, D., Esmear, T., Oosthuizen, C. B., Reid, A. M., Nel, M., et al. (2020). Anti-SARS-CoV natural products with the potential to inhibit SARS-CoV-2 (COVID-19). Front. Pharmacol. 11:1-20. doi: 10.3389/fphar.2020. 561334

Verpoorte, R., and Memelink, J. (2002). Engineering secondary metabolite production in plants. Curr. Opin. Biotechnol. 13, 181-187. doi: 10.1016/S09581669(02)00308-7

Vranová, E., Coman, D., and Gruissem, W. (2013). Network analysis of the MVA and MEP pathways for isoprenoid synthesis. Annu. Rev. Plant Biol. 64, 665-700. doi: 10.1146/annurev-arplant-050312-120116

Wallaart, T. E., Bouwmeester, H. J., Hille, J., Poppinga, L., and Maijers, N. C. A. (2001). Amorpha-4,11-diene synthase: cloning and functional expression of a key enzyme in the biosynthetic pathway of the novel antimalarial drug artemisinin. Planta 212, 460-465. doi: 10.1007/s0042500 00428

Wang, B., Beyraghdar Kashkooli, A., Sallets, A., Ting, H. M., de Ruijter, N. C. A., Olofsson, L., et al. (2016). Transient production of artemisinin in Nicotiana 
benthamiana is boosted by a specific lipid transfer protein from a. annua. Metab. Eng. 38, 159-169. doi: 10.1016/j.ymben.2016.07.004

Wang, B., Hou, D., Liu, Q., Wu, T., Guo, H., Zhang, X., et al. (2015). Artesunate sensitizes ovarian cancer cells to cisplatin by downregulating RAD51. Cancer Biol. Ther. 16, 1548-1556. doi: 10.1080/15384047.2015.1071738

Wang, J., Huang, L., Li, J., Fan, Q., Long, Y., Li, Y., et al. (2010). Artemisinin directly targets malarial mitochondria through its specific mitochondrial activation. PLoS One 5:e9582. doi: 10.1371/journal.pone.0009582

Wang, J., Zhang, C. J., Chia, W. N., Loh, C. C. Y., Li, Z., Lee, Y. M., et al. (2015). Haem-activated promiscuous targeting of artemisinin in Plasmodium falciparum. Nat. Commun. 6:10111. doi: 10.1038/ncomms10111

Wang, J. S., Wang, M. J., Lu, X., Zhang, J., Liu, Q. X., Zhou, D., et al. (2020). Artesunate inhibits epithelial-mesenchymal transition in nonsmall-cell lung cancer (NSCLC) cells by down-regulating the expression of BTBD7. Bioengineered 11, 1197-1207. doi: 10.1080/21655979.2020.183 4727

Wang, K., Zhang, Z., Wang, M., Cao, X., Qi, J., Wang, D., et al. (2019). Role of GRP78 inhibiting artesunate-induced ferroptosis in KRAS mutant pancreatic cancer cells. Drug Des. Devel. Ther. 13, 2135-2144. doi: 10.2147/DDDT. S199459

Wang, L., Li, J., Shi, X., Li, S., Tang, P. M.-K., Li, Z., et al. (2019). Antimalarial dihydroartemisinin triggers autophagy within HeLa cells of human cervical cancer through Bcl-2 phosphorylation at Ser70. Phytomedicine 52, 147-156. doi: 10.1016/j.phymed.2018.09.221

Wang, L., Liu, L., Wang, J., and Chen, Y. (2017). Inhibitory effect of artesunate on growth and apoptosis of gastric cancer cells. Arch. Med. Res. 48, 623-630. doi: 10.1016/j.arcmed.2018.03.004

Wang, S. J., Gao, Y., Chen, H., Kong, R., Jiang, H. C., Pan, S. H., et al. (2010). Dihydroartemisinin inactivates NF-kB and potentiates the anti-tumor effect of gemcitabine on pancreatic cancer both in vitro and in vivo. Cancer Lett. 293, 99-108. doi: 10.1016/j.canlet.2010.01.001

Wang, S.-J., Sun, B., Cheng, Z.-X., Zhou, H.-X., Gao, Y., Kong, R., et al. (2011). Dihydroartemisinin inhibits angiogenesis in pancreatic cancer by targeting the NF-кB pathway. Cancer Chemother. Pharmacol. 68, 1421-1430. doi: 10.1007/ s00280-011-1643-7

Wani, K. I., Choudhary, S., Zehra, A., Naeem, M., Weathers, P., and Aftab, T. (2021). Enhancing artemisinin content in and delivery from Artemisia annua: a review of alternative, classical, and transgenic approaches. Planta 254, 1-15. doi: 10.1007/s00425-021-03676-3

Weathers, L. D. (2003). Tetraploid Artemisia annua hairy roots produce more artemisinin than diploids. Plant Cell Rep. 21, 809-813. doi: 10.1007/s00299003-0587-8

Weathers, P. J., Bunk, G., and McCoy, M. C. (2005). The effect of phytohormones on growth and artemisinin production in Artemisia annua hairy roots. Vitr. Cell. Dev. Biol. Plant 41, 47-53. doi: 10.1079/IVP2004604

Wen, L., Liu, L., Wen, L., Yu, T., and Wei, F. (2018). Artesunate promotes G2/M cell cycle arrest in MCF7 breast cancer cells through ATM activation. Breast Cancer 25, 681-686. doi: 10.1007/s12282-018-0873-5

Westfall, P. J., Pitera, D. J., Lenihan, J. R., Eng, D., Woolard, F. X., Regentin, R., et al. (2012). Production of amorphadiene in yeast, and its conversion to dihydroartemisinic acid, precursor to the antimalarial agent artemisinin. Proc. Natl. Acad. Sci. U.S.A. 109, 111-118. doi: 10.1073/pnas.1110740109

Williamson, G., and Kerimi, A. (2020). Testing of natural products in clinical trials targeting the SARS-CoV-2 (Covid-19) viral spike protein-angiotensin converting enzyme-2 (ACE2) interaction. Biochem. Pharmacol. 178:114123. doi: $10.1016 /$ j.bcp. 2020.114123

Willoughby, J. A., Sundar, S. N., Cheung, M., Tin, A. S., Modiano, J., and Firestone, G. L. (2009). Artemisinin blocks prostate cancer growth and cell cycle progression by disrupting Sp1 interactions with the cyclin-dependent kinase-4 (CDK4) promoter and inhibiting CDK4 gene expression. J. Biol. Chem. 284, 2203-2213. doi: 10.1074/jbc.M804491200

Wu, J., Hu, D., Yang, G., Zhou, J., Yang, C., Gao, Y., et al. (2011). Down-regulation of BMI-1 cooperates with artemisinin on growth inhibition of nasopharyngeal carcinoma cells. J. Cell. Biochem. 112, 1938-1948. doi: 10.1002/jcb.23114

Wu, L., Cheng, Y., Deng, J., Tao, W., and Ye, J. (2019). Dihydroartemisinin inhibits proliferation and induces apoptosis of human hepatocellular carcinoma cell by upregulating tumor necrosis factor via JNK/NF-KB pathways. evidence-based Complement. Altern. Med. 2019:327. doi: 10.1155/2019/9581327
Wu, T., Wu, S., Yin, Q., Dai, H., Li, S., Dong, F., et al. (2011). Biosynthesis of amorpha-4,11-diene, a precursor of the antimalarial agent artemisinin, in Escherichia coli through introducing mevalonate pathway. Shengwu Gongcheng Xuebao/Chinese J. Biotechnol. 27, 1040-1048.

Xie, D. Y., Ma, D. M., Judd, R., and Jones, A. L. (2016). Artemisinin biosynthesis in Artemisia annua and metabolic engineering: questions, challenges, and perspectives. Phytochem. Rev. 15, 1093-1114. doi: 10.1007/s11101-016-9480-2

Xiong, Z., Sun, G., Zhu, C., Cheng, B., Zhang, C., Ma, Y., et al. (2010). Artemisinin, an anti-malarial agent, inhibits rat cardiac hypertrophy via inhibition of NF- $\mathrm{kB}$ signaling. Eur. J. Pharmacol. 649, 277-284. doi: 10.1016/j.ejphar.2010.09.018

Xu, H., He, Y., Yang, X., Liang, L., Zhan, Z., Ye, Y., et al. (2007). Anti-malarial agent artesunate inhibits TNF- $\alpha$-induced production of proinflammatory cytokines via inhibition of NF- $\mathrm{kB}$ and PI3 kinase/Akt signal pathway in human rheumatoid arthritis fibroblast-like synoviocytes. Rheumatology 46, 920-926. doi: 10.1093/rheumatology/kem014

Yan, A., Pan, J., An, L., Gan, Y., and Feng, H. (2012). The responses of trichome mutants to enhanced ultraviolet-B radiation in Arabidopsis thaliana. J. Photochem. Photobiol. B Biol. 113, 29-35. doi: 10.1016/j.jphotobiol.2012.04. 011

Yang, C. Q., Fang, X., Wu, X. M., Mao, Y. B., Wang, L. J., and Chen, X. Y. (2012). Transcriptional regulation of plant secondary metabolism. J. Integr. Plant Biol. 54, 703-712. doi: 10.1111/j.1744-7909.2012.01161.x

Yang, N., Di Tan, S. H., Ng, S., Shi, Y., Zhou, J., Tan, K. S. W., et al. (2014). Artesunate induces cell death in human cancer cells via enhancing lysosomal function and lysosomal degradation of ferritin. J. Biol. Chem. 289, 33425-33441. doi: 10.1074/jbc.M114.564567

Yang, R.-Y., Feng, L.-L., Yang, X.-Q., Yin, L.-L., Xu, X.-L., and Zeng, Q.-P. (2008). Quantitative transcript profiling reveals down-regulation of a sterol pathway relevant gene and overexpression of artemisinin biogenetic genes in transgenic Artemisia annua plants. Planta Med. 74, 1510-1516. doi: 10.1055/s-20081081333

Yao, Z., Bhandari, A., Wang, Y., Pan, Y., Yang, F., Chen, R., et al. (2018). Dihydroartemisinin potentiates antitumor activity of 5 -fluorouracil against a resistant colorectal cancer cell line. Biochem. Biophys. Res. Commun. 501, 636-642. doi: 10.1016/j.bbrc.2018.05.026

Ye, V. M., and Bhatia, S. K. (2012). Metabolic engineering for the production of clinically important molecules: omega-3 fatty acids, artemisinin, and taxol. Biotechnol. J. 7, 20-33. doi: 10.1002/biot.201100289

Yin, S., Yang, H., Zhao, X., Wei, S., Tao, Y., Liu, M., et al. (2020). Antimalarial agent artesunate induces G0/G1 cell cycle arrest and apoptosis via increasing intracellular ROS levels in normal liver cells. Hum. Exp. Toxicol. 39, 1681-1689. doi: 10.1177/0960327120937331

Yin, X., Liu, Y., Qin, J., Wu, Y., Huang, J., Zhao, Q., et al. (2021). Artesunate suppresses the proliferation and development of estrogen receptor- $\alpha$-positive endometrial cancer in HAND2-dependent pathway. Front. Cell Dev. Biol. 8:1-14. doi: 10.3389/fcell.2020.606969

Yu, C., Sun, P., Zhou, Y., Shen, B., Zhou, M., Wu, L., et al. (2019). Inhibition of AKT enhances the anti-cancer effects of artemisinin in clear cell renal cell carcinoma. Biomed. Pharmacother. 118:109383. doi: 10.1016/j.biopha.2019.109383

Yu, L., Chen, J. F., Shuai, X., Xu, Y., Ding, Y., Zhang, J., et al. (2016). Artesunate protects pancreatic beta cells against cytokine-induced damage via SIRT1 inhibiting NF-кB activation. J. Endocrinol. Invest. 39, 83-91. doi: 10.1007/ s40618-015-0328-1

Yuan, Y., Liu, W., Zhang, Q., Xiang, L., Liu, X., Chen, M., et al. (2015). Overexpression of artemisinic aldehyde $\Delta 11$ (13) reductase geneenhanced artemisinin and its relative metabolite biosynthesis in transgenic Artemisia annua L. Biotechnol. Appl. Biochem. 62, 17-23. doi: 10.1002/bab. 1234

Zeng, Q. P., and Zhang, P. Z. (2011). Artesunate mitigates proliferation of tumor cells by alkylating heme-harboring nitric oxide synthase. Nitric Oxide Biol. Chem. 24, 110-112. doi: 10.1016/j.niox.2010.12.005

Zeng, X., Zhang, Y., Wang, K., Tao, L., Zou, M., Chen, N., et al. (2017). Artesunate suppresses RANKL-induced osteoclastogenesis through inhibition of PLC $\gamma 1$ $\mathrm{Ca} 2+-\mathrm{NFATc1}$ signaling pathway and prevents ovariectomy-induced bone loss. Biochem. Pharmacol. 124, 57-68. doi: 10.1016/j.bcp.2016.10.007

Zhang, H. T., Wang, Y. L., Zhang, J., and Zhang, Q. X. (2014). Artemisinin inhibits gastric cancer cell proliferation through upregulation of p53. Tumor Biol. 38, 639-646. doi: 10.1002/cbin.10244 
Zhang, J., Sun, X., Wang, L., Wong, Y. K., Lee, Y. M., Zhou, C., et al. (2018). Artesunate-induced mitophagy alters cellular redox status. Redox Biol. 19, 263-273. doi: 10.1016/j.redox.2018.07.025

Zhang, L., Jing, F., Li, F., Li, M., Wang, Y., Wang, G., et al. (2009). Development of transgenic Artemisia annua (chinese wormwood) plants with an enhanced content of artemisinin, an effective anti-malarial drug, by hairpin-RNAmediated gene silencing. Biotechnol. Appl. Biochem. 52:199. doi: 10.1042/ BA20080068

Zhang, L. X., Liu, Z. N., Ye, J., Sha, M., Qian, H., Bu, X. H., et al. (2014). Artesunate exerts an anti-immunosuppressive effect on cervical cancer by inhibiting PGE2 production and Foxp3 expression. Cell Biol. Int. 38, 639-646.

Zhang, P., Luo, H. S., Li, M., and Tan, S. Y. (2015). Artesunate inhibits the growth and induces apoptosis of human gastric cancer cells by downregulating COX-2. Onco. Targets. Ther. 8, 845-854. doi: 10.2147/OTT.S81041

Zhang, Y., Nowak, G., Reed, D. W., and Covello, P. S. (2011). The production of artemisinin precursors in tobacco. Plant Biotechnol. J. 9, 445-454. doi: 10.1111/ j.1467-7652.2010.00556.x

Zhang, Y., Teoh, K. H., Reed, D. W., Maes, L., Goossens, A., Olson, D. J. H., et al. (2008). The molecular cloning of artemisinic aldehyde $\Delta 11$ (13) reductase and its role in glandular trichome-dependent biosynthesis of artemisinin in Artemisia annua. J. Biol. Chem. 283, 21501-21508. doi: 10.1074/jbc. M803090200

Zhang, Y. S., Ye, H. C., Liu, B. Y., Wang, H., and Li, G. F. (2005). Exogenous GA3 and flowering induce the conversion of artemisinic acid to artemisinin in Artemisia annua plants. Russ. J. Plant Physiol. 52, 58-62. doi: 10.1007/s11183005-0009-6

Zhao, F., Vakhrusheva, O., Markowitsch, S. D., Slade, K. S., Tsaur, I., Cinatl, J., et al. (2020). Artesunate impairs growth in cisplatin-resistant bladder cancer cells by cell cycle arrest, apoptosis and autophagy induction. Cells 9, 1-19. doi: $10.3390 /$ cells 9122643

Zhao, J., Davis, L. C., and Verpoorte, R. (2005). Elicitor signal transduction leading to production of plant secondary metabolites. Biotechnol. Adv. 23, 283-333. doi: 10.1016/j.biotechadv.2005.01.003

Zhao, Y., Jiang, W., Li, B., Yao, Q., Dong, J., Cen, Y., et al. (2011). Artesunate enhances radiosensitivity of human non-small cell lung cancer A549 cells via increasing NO production to induce cell cycle arrest at G 2/M phase. Int. Immunopharmacol. 11, 2039-2046. doi: 10.1016/j.intimp.2011.08.017

Zheng, Y.-Y., Ma, Y. T., Zhang, J. Y., and Xie, X. (2020). COVID-19 and the cardiovascular system. Nat. Rev. Cardiol. 17, 259-260. doi: 10.1038/s41569020-0360-5

Zhou, H. J., Wang, W. Q., Wu, G. D., Lee, J., and Li, A. (2007). Artesunate inhibits angiogenesis and downregulates vascular endothelial growth factor expression in chronic myeloid leukemia K562 cells. Vascul. Pharmacol. 47, 131-138. doi: 10.1016/j.vph.2007.05.002

Zhou, M., and Memelink, J. (2016). Jasmonate-responsive transcription factors regulating plant secondary metabolism. Biotechnol. Adv. 34, 441-449. doi: 10. 1016/j.biotechadv.2016.02.004
Zhou, X., Chen, Y., Wang, F., Wu, H., Zhang, Y., Liu, J., et al. (2020a). Artesunate induces autophagy dependent apoptosis through upregulating ROS and activating AMPK-mTOR-ULK1 axis in human bladder cancer cells. Chem. Biol. Interact. 331:109273. doi: 10.1016/j.cbi.2020.109273

Zhou, X., Sun, W. J., Wang, W. M., Chen, K., Zheng, J. H., Lu, M. D., et al. (2013). Artesunate inhibits the growth of gastric cancer cells through the mechanism of promoting oncosis both in vitro and in vivo. Anticancer. Drugs 24, 920-927. doi: 10.1097/CAD.0b013e328364a109

Zhou, X., Zijlstra, S. N., Soto-Gamez, A., Setroikromo, R., and Quax, W. J. (2020b). Artemisinin derivatives stimulate DR5-specific TRAIL-induced apoptosis by regulating wildtype P53. Cancers (Basel). 12:2514. doi: 10.3390/ cancers 12092514

Zhou, Y., Gilmore, K., Ramirez, S., Settels, E., Gammeltoft, K. A., Pham, L. V., et al. (2021). In vitro efficacy of artemisinin-based treatments against SARS-CoV-2. Sci. Rep. 11, 1-14. doi: 10.1038/s41598-021-93361-y

Zhou, Y., Wang, X., Zhang, J., He, A., Wang, Y. L., Han, K., et al. (2017). Artesunate suppresses the viability and mobility of prostate cancer cells through UCA1, the sponge of miR-184. Oncotarget 8, 18260-18270. doi: 10.18632/oncotarget. 15353

Zhu, S., Liu, W., Ke, X., Li, J., Hu, R., Cui, H., et al. (2014). Artemisinin reduces cell proliferation and induces apoptosis in neuroblastoma. Oncol. Rep. 32, 1094-1100. doi: 10.3892/or.2014.3323

Zhu, Z., Cai, T., Fan, L., Lou, K., Hua, X., Huang, Z., et al. (2020). Clinical value of immune-inflammatory parameters to assess the severity of coronavirus disease 2019. Int. J. Infect. Dis. 95, 332-339. doi: 10.1016/j.ijid.2020. 04.041

Zuo, W., Wang, Z. Z., and Xue, J. (2014). Artesunate induces apoptosis of bladder cancer cells by miR-16 regulation of COX-2 expression. Int. J. Mol. Sci. 15, 14298-14312. doi: 10.3390/ijms150814298

Conflict of Interest: The authors declare that the research was conducted in the absence of any commercial or financial relationships that could be construed as a potential conflict of interest.

Publisher's Note: All claims expressed in this article are solely those of the authors and do not necessarily represent those of their affiliated organizations, or those of the publisher, the editors and the reviewers. Any product that may be evaluated in this article, or claim that may be made by its manufacturer, is not guaranteed or endorsed by the publisher.

Copyright (c) 2022 Farmanpour-Kalalagh, Beyraghdar Kashkooli, Babaei, Rezaei and van der Krol. This is an open-access article distributed under the terms of the Creative Commons Attribution License (CC BY). The use, distribution or reproduction in other forums is permitted, provided the original author(s) and the copyright owner(s) are credited and that the original publication in this journal is cited, in accordance with accepted academic practice. No use, distribution or reproduction is permitted which does not comply with these terms. 